\title{
Las estructuras arqueológicas del Cerro Huallío en Cachicadán, Sierra Norte del Perú
}

\author{
Ismael Pérez Calderón
}

\begin{abstract}
Resumen
Se busca divulgar para conocer y comprender parte de la importancia histórica sobre un conjunto de restos arqueológicos existentes y visibles a nivel de superficie de los cerros Huallío y Chiragbal, éste último considerado como uno de los santuarios prehispánicos de mayor magnitud y transcendencia cultural en la sierra norte de los Andes centrales. Los restos consisten en cuevas, tumbas, mausoleos y nichos $o$ "ventanillas" labrados en peñas y afloramientos rocosos; canteras, huancas, plataformas ceremoniales, unidades habitacionales, caminos y zanjas, agrupados en la categoría de estructuras, dispersas en un espacio aproximado de 57 hectáreas, al que se podría denominar área cultural del complejo arqueológico del Huallío. El trabajo es producto de la observación directa, con pobladores del lugar, utilizando celulares para la toma de fotografías y coordenadas que ilustran el presente reporte. Palabras clave: Estructuras funerarias, Huallio, Chiragbal, Culle, mausoleo, tumba.
\end{abstract}

\begin{abstract}
ARCHAEOLOGICAL STRUCTURES OF CERRO HUALLÍO, CACHICADÁN, NORTHERN HIGHLANDS OF PERU

It is sought to disseminate to know and understand part of the historical importance on a set of existing and visible archaeological remains at the surface level of the Huallio and Chiragbal hills, the latter considered as one of the pre-Hispanic sanctuaries of greater magnitude and cultural significance in the mountains North of the central Andes. he remains consist of caves, tombs, mausoleums and niches or "windows" carved into rocks and rocky outcrops; quarries, huancas, ceremonial platforms, housing units, roads and ditches, grouped in the category of structures, dispersed in an area of approximately 57 hectares, which could be called the cultural area of the archaeological complex of Huallio. The work is the product of direct observation, with locals, using cell phones to take photographs and coordinates that illustrate this report.

Keywords: Funeral structures, Huallio, Chiragbal, Culle, mausoleum, tomb.
\end{abstract}

Ismael Rérez Calderón • Universidad Nacional de San Cristóbal de Huamanga, Ciudad Universitaria S/N, Ayacucho - Perú, zismaelunsch@hotmail.com 


\section{Introducción}

El presente trabajo es resultado de unas visitas efectuadas en compañía de pobladores de Cachicadán para conocer y entender el potencial turístico de la localidad, a fin de promover la programación de posteriores trabajos de investigación, conservación y puesta en valor del patrimonio dejado por nuestros antepasados prehispánicos que ocuparon las alturas de Cachicadán en Santiago de Chuco la Libertad.

En la sierra norte de los Andes Peruanos, cerro Huallio ocupa un espacio privilegiado rodeado de quebradas y ríos que drenan a los ríos Tablachaca o Chuquicara, que discurre de este a oeste para unirse al río Santa, formando un singular valle interandino, escenario del surgimiento del centro arqueológico de La Galgada que representa a las primeras agrupaciones sedentarias con arquitectura piramidal de carácter monumental, reflejo de la existencia de una sociedad segmentada en grupos sociales y lideraba por grupos de poder, coetáneos con los emblemáticos sitios de Caral, Kotosh y Huaca Prieta, con los que debió de tener contacto y relaciones culturales.

Las estructuras arqueológicas que a continuación se describen se encuentran en buen estado de conservación, como para establecer un circuito turismo para el desarrollo social y económico de la región. En cuanto a la antigüedad, se atribuidas al primer al primer milenio y mitad del segundo milenio d. C.

\section{Antecedentes}

En el siglo XVI, cuando, Pedro Cieza de León en la primera parte de la Crónica del Perú: Capítulos LXXXI y LXXXII, narra de los pueblos que existían entre Guamachuco y Conchucos unidos por caminos que cruzaban cerros, pampas, laderas y quebradas, se refiere sin duda a los pueblos establecidos en las cercanías del camino principal que une a Guamachuco con Conchucos, el cual pasa por Rayambal cerca del cerro Huayllio y otros asentamientos poblacionales.

Para el siglo XVII, Lucila Castro de Trelles en la edición, estudio preliminar y notas a la Relación de la religión y ritos del Perú hecha por los padres agustinos alcanza interesantes referencias sobre las huacas e ídolos que existía, en el antiguo territorio de los Guamachucos, siendo cerro Huallio uno de los centros religiosos y menciona que "Entre unas peñas altas hallaron los padres otra cueva no muy honda donde estaba otro ydolo o guaca llamada Guallio... al que mochaban y adoraban quando hilaban la ropa del Inga Guaynacap y los otros yngas; y ofrecíale coyes y untaban las peñas con la sangre; a éste venyan a mochar desde Caxamalca y aun poco avía que avían sacrificado porque hallamos la sangre recién echada. Para entrar a ella era con gran peligro, pero el padre frai Juan Ramirez y frai Alonso Maldonado, con gran dificultad entraron y con gran peligro porque a deslizarse poquito cayan cien myll estados de hondo, y en verdad que cuando se vieron dentro que les pesó visto el peligro, pero con favor de Dios derribaron el ydolo y de allí abaxo y desbarataron la cueva; 
ofrecían también a este Guallio huesos y torteros y cuernos y husos con que hacen la ropa y cumbi" (Castro de Trelles 1992:22-23). De la referida cita deducimos la importancia del Huallio en la época prehispánica y las estructuras que existían antes de la llegada de los Incas.

En la década del cuarenta del siglo XX, Horkeimer (1944), difunde por primera vez a las ventanillas del cerro Huallio, en su libro "vistas arqueológicas del noroeste del Perú". Posteriormente Ravines (1984), agrupa a las ventanillas como una tradición de la cultura Cajamarca. Zaki (1983) y Krzanowski (2006) identifican y registran un conjunto de sitios arqueológicos en el curso superior de los ríos Moche y Chicama; Pérez $(1999,2012)$, incrementa información sobre las ventanillas del tipo Cajamarca, dando a conocer otros sitios que rodean al cerro Huallio; Ravines $(2010,2017)$ brinda una valiosa información sobre arte rupestre y canteras con artefactos líticos en Quiruvilca y, Briceño (2006), hace referencia de estructuras precerámicas en las cercanías del cerro Huallio.

\section{Geología}

Representado por afloramientos tempranos de la formación Chicama, visible en la margen izquierda superior del río Angasmarca que se sobrepone a las formaciones del Cretáceo Superior representado por la formación Huaylas, mientras que en las cercanías aflora la formación Chimu del Cretáceo Inferior sobre la que aparece la formación Calipuy del Cretáceo Superior y parte del Terciario Inferior, se extiende cubriendo más del 70\% del cuadrángulo de Santiago de Chuco, que según Cossio (1964: 14) se caracterizada por contener una serie de lutitas bien laminadas, de aspecto pizarroso, de color gris oscuro a negro, con ocasionales intercalaciones de areniscas y cuarcitas claras y de limonitas gris parduzcas por el intemperismo. A la formación Calipuy se asocia los filamentos de carbón mineral que aflora en Huallio y Sagarball, tan igual que en el alto Chicama y la Galgada.

\section{Geomorfología}

Corresponde a la parte alta de Cachicadán, donde precisamente el Huallio es el cerro de mayor altura $(3990 \mathrm{msnm})$ con laderas accesibles conectas al oeste con cerro Caucallate, al oeste con cerro la Sala o Sagarball, al norte y sur por una cadena de cerros y lomas de suaves pendientes que descienden a las microcuencas formadas por los ríos Angasmarca y San Antonio, en toda la extensión existe afloramientos arcillosos y filtraciones de agua termales en las faldas de los cerros cercanos de Huacas y la Botica.

\section{Entorno geográfico}

Una típica vegetación de puna constituida por ichu, cubre afloramientos de basalto, andesita, cuarzo, arcillas de distintos colores, y carbón mineral con brechas o filamentos aprovechadas al parecer desde la época prehispánica, a lo que se 
incluye la introducción de plantas de pinos que, si bien retiene la humedad y forma un bosque favorable para la fauna silvestre, impide apreciar el paisaje cultural con árboles nativos que nos dejaron los antiguos pobladores que ocuparon el lugar. Las aguas que en tiempo de lluvia discurren por las laderas del Huallío alimentan el cauce de pequeñas quebradas que confluyen a los ríos San Antonio/Huaychaca y Angasmarca/Huanda, tributarios del río Tablachaca o Chuquicara, que incrementa el caudal del río Santa, frontera de los departamentos de Ancash y la Libertad.

\section{Resultados: Distribución de estructuras arqueológicas}

Las estructuras registradas se encuentran en el lados oriental y occidental por donde se accede a la cima donde se encuentra los restos del poblado que ocupa la parte más elevada del cerro, hacia el lado sur es inaccesible con presencia de peñascos, mientras que hacia el lado norte la ladera de suave pendiente conserva los restos de un viejo poblado conectado al cerro Sagarball que tiene también restos de otro poblado. De manera general iniciando el recorrido por el lado oeste se puede distinguir las siguientes estructuras:

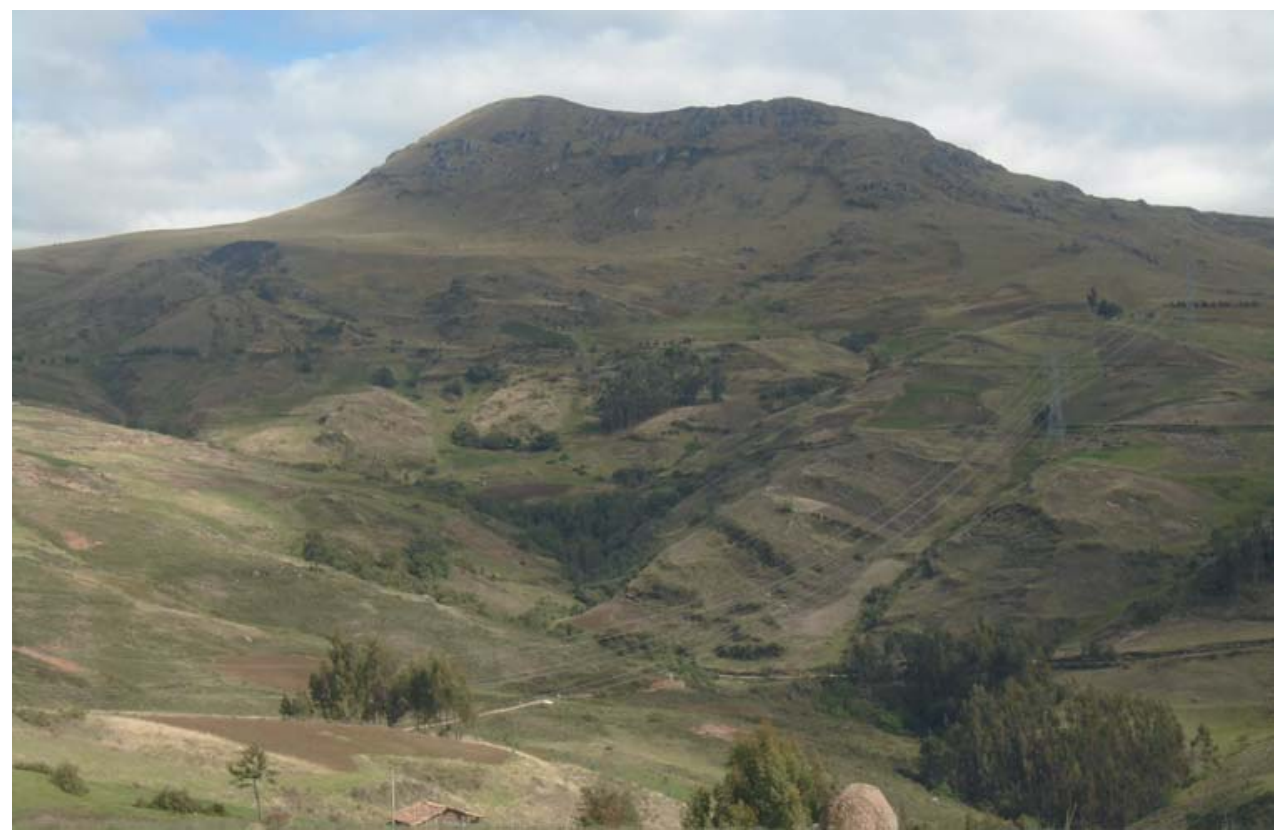

Figura 1: Panorámica del lado inaccesible del cerro Huayllio, visto desde Algallama.

E1. Cueva. Dispuesta en la falda este del cerro próximo al cauce de una quebrada, la boca da hacia el cerro Sagarball, el interior esta acondicionada con un muro que forma un acceso, corresponde sin duda a un lugar de entierro el cual ha sido disturbado quedando sola forma cuadrangular del recinto interno. 


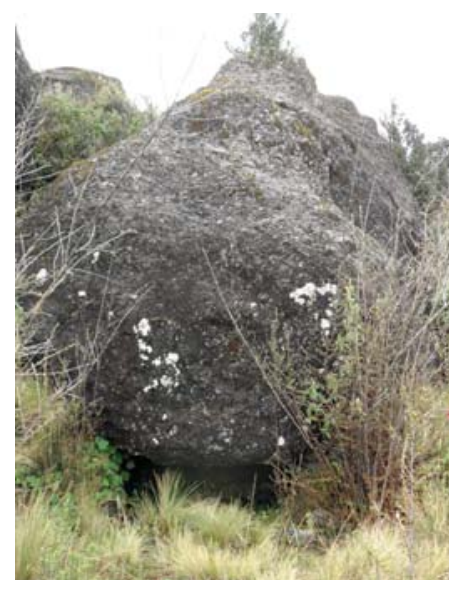

Figura 2: Detalle del acceso al interior de la cueva.

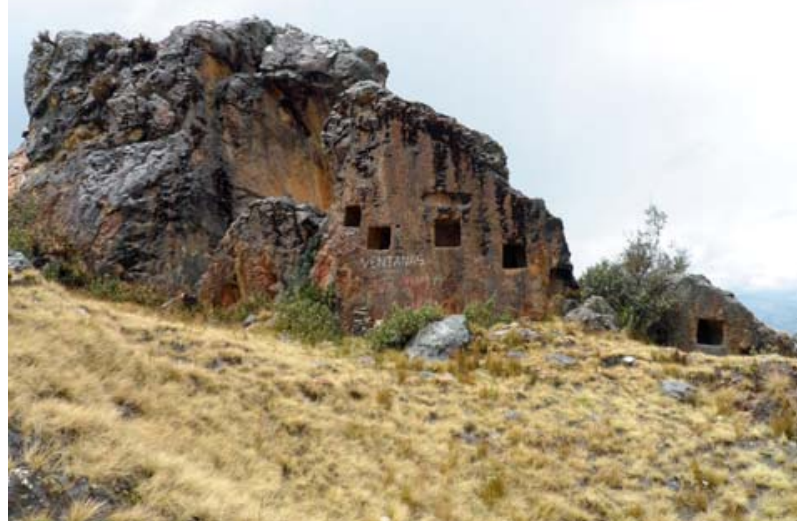

Figura 3: E2. Ventanillas y pozos (Coordenadas UTM: $818028 \mathrm{E} / 9104988 \mathrm{~N}, 3799 \mathrm{msnm}$.

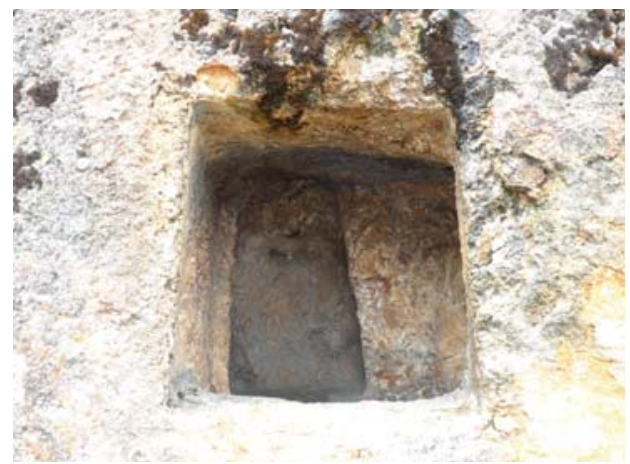

Figura 4: Detalle de una ventanilla con doble concavidad.

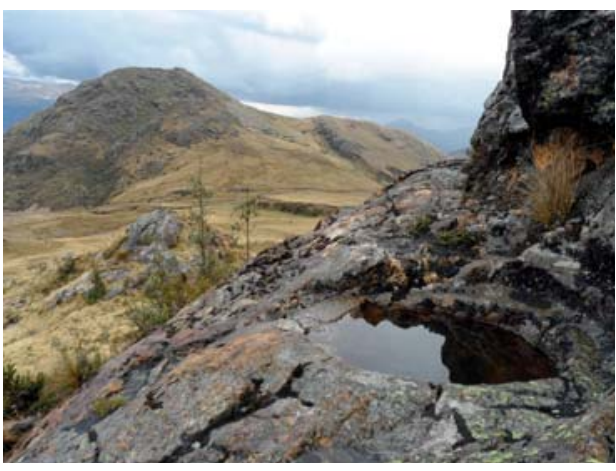

Figura 5: Poza circular en el lado posterior de la peña con ventanillas.
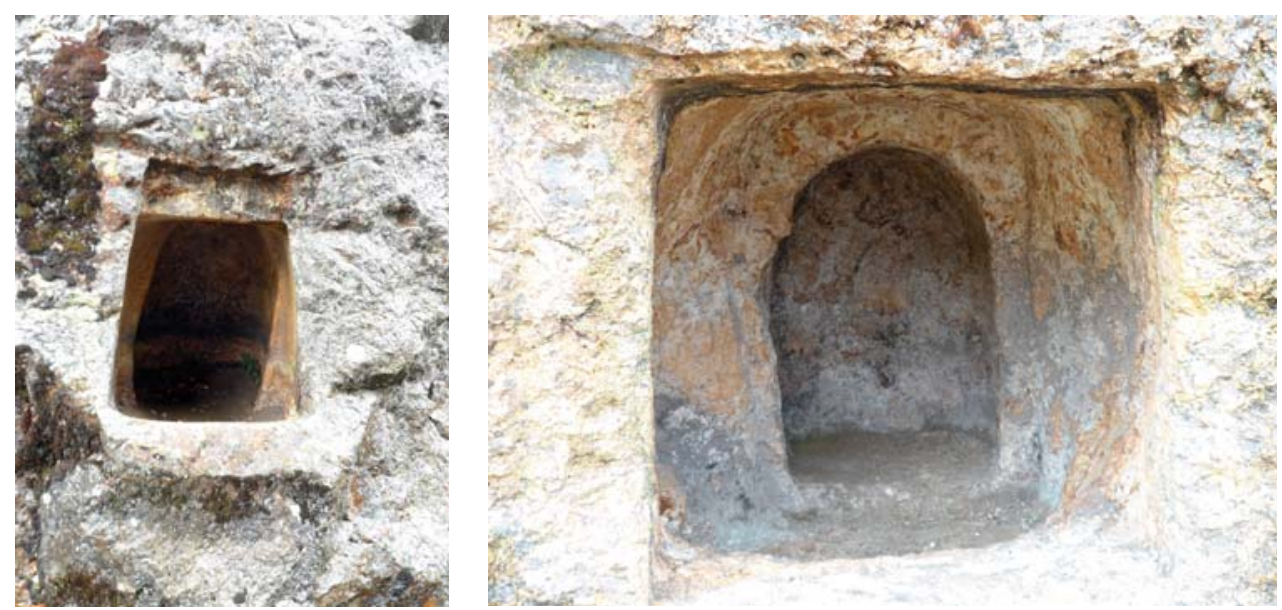

Figuras 6 y 7: Ventanillas: trapezoidal y cuadrada ambas con doble y triple fondo. 

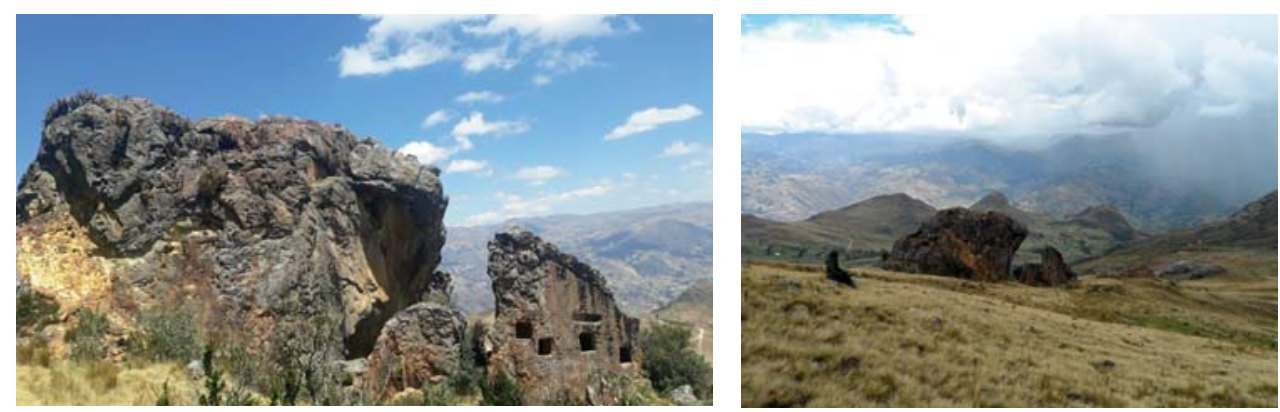

Figuras 8 y 9: Conjunto de rocas asociadas a las ventanillas. Nótese el bloque de mayor tamaño en aparente forma de un animal (sapo) con cabeza hacia adelante.

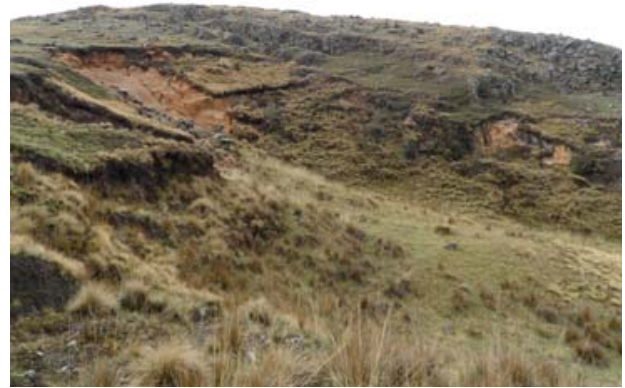

Figura 10: Ladera con hundimiento geológico, próximo a la cima del Huallio.

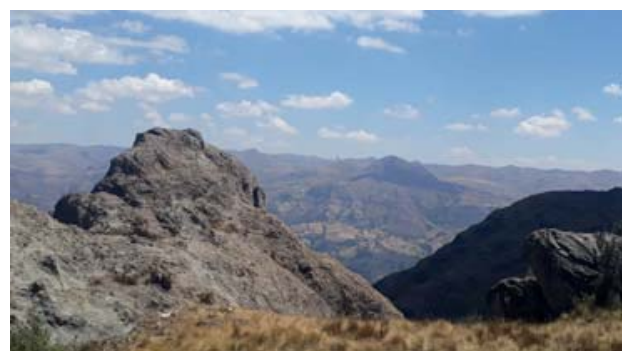

Figura 12: E4. Superficie y peña que contiene restos de tumbas disturbadas. La peña presenta además talladuras en forma de caminos y pocitos ceremoniales.

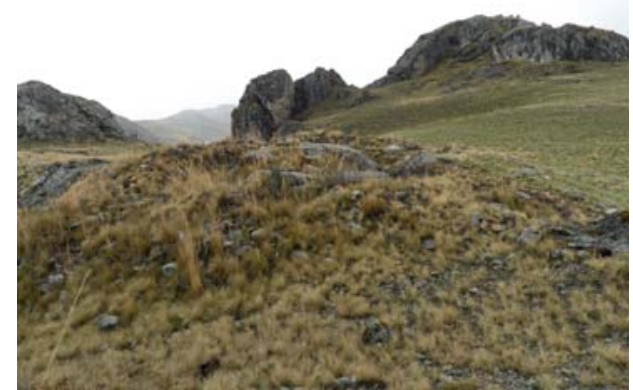

Figura 11: Bloques de piedra dispersos en el centro de posible área funeraria, lado superior este del cerro Huallío.

E2. Ventanillas. Se trata de un bloque de piedra cuyo lado labrado presenta siete nichos a los que se conoce como ventanillas, pero en realidad son concavidades hechas para entierros de personajes de élite o selectivos. El lado posterior del bloque con ventanillas presenta un pozo circular con graderías de carácter ceremonial. La superficie está disturbada, existe una zanja que parece corresponder a la existencia de galerías subterráneas.

E3. Estructura disturbada en montículo (Coordenadas UTM: $8118222 \mathrm{E} / 9104922 \mathrm{~N}), 3864 \mathrm{msnm}$. En la superficie no existe restos óseos ni fragmentos de cerámica, pero por la forma y disposición de piedras en el centro de un pequeño montículo, se plante la hipótesis que se trata de una tumba de aspecto circular excavada bajo suelo estéril, la cual al ser disturbada quedaron dispersos las 

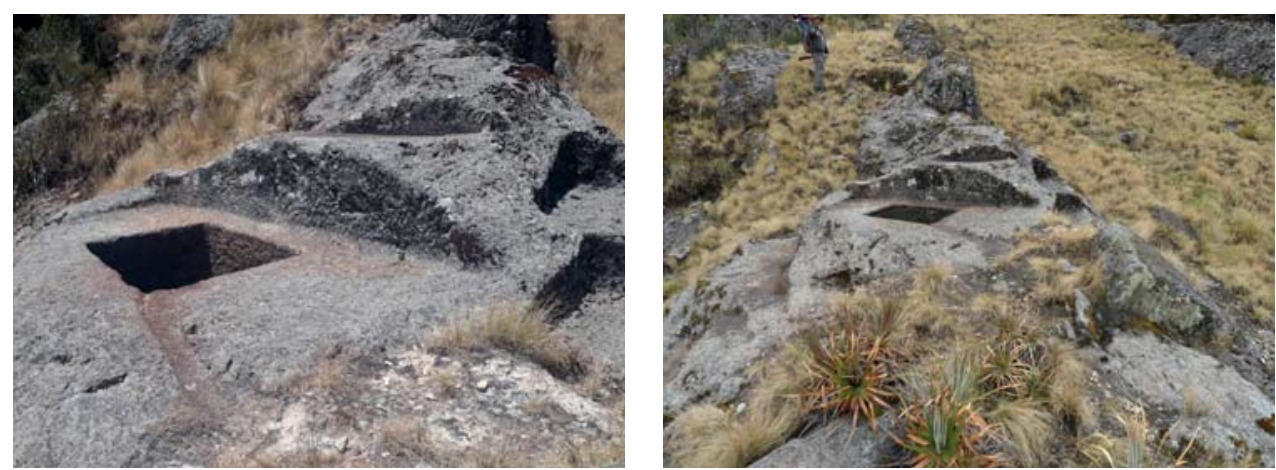

Figuras 13 y 14: Detalle de la estructura funeraria disturbada, el pozo talladuras en distintos niveles recuerda las formas de "intihuatanas".

piedras que formaban parte de las tapas y paredes hechas con grandes bloques de piedra.

E4. Tumbas disturbadas (Coordenadas UTM: $818182 \mathrm{E} / 910497 \mathrm{~N})$, $3854 \mathrm{msnm}$. Los restos de una las estructuras funerarias en la parte superior junto a una peña en forma de un pequeño cerro, aproximadamente a $60 \mathrm{~m}$ al este de la E2, la otra tumba disturbada

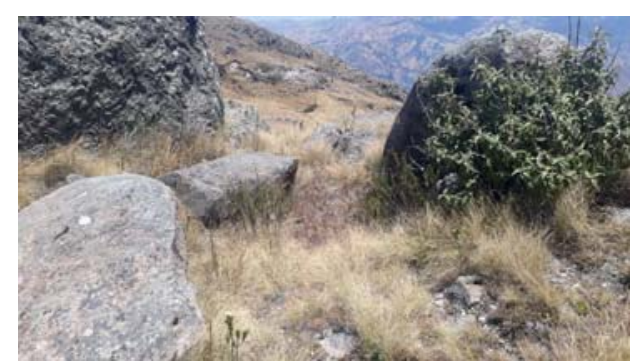

Figura 15: Bloque de piedras talladas y sin tallar en un espacio hundido características de las tumbas disturbadas. está es de forma cuadrangular tallada en el lado norte de la misma peña. En ambos se percibe la hendidura donde la humedad que se concentra permite el crecimiento de plantas "cortaderas", tipo totora. Las tapas se encuentran dispersas en la ladera próximas a las áreas disturbadas, donde probablemente existan otras tumbas.

E5. Tumba disturbada, localizada aproximadamente a $50 \mathrm{~m}$ al este (Coordenadas UTM: 18177E/9105026N), $3843 \mathrm{msnm}$., descendiendo por la E4, aunque también se llega de manera directa ascendiendo por el lado norte de la E1. La estructura lo integran un pozo, canal y graderías talladas en el mismo afloramiento rocoso, en el entorno existen piedras labradas que formaban parte de la tapa. De manera general se aprecia como fuente de agua y las graderías guardan semejanza con las variedades de "intihuatana".

E6. Estructura disturbada, corresponde a una tumba megalítica, (Coordenadas UTM: 818287E/9104956N, 3883msnm., a $100 \mathrm{~m}$ al oeste ascendiendo desde la E5 y $50 \mathrm{~m}$ desde la estructura 3. Consiste en varias piedras labradas dispersas alrededor de un espacio hundido aparentemente disturbado, junto a otros bloques de piedras paradas. No se observa la boca de la tumba, pero no se descarta que corresponda a una tumba megalítica. 

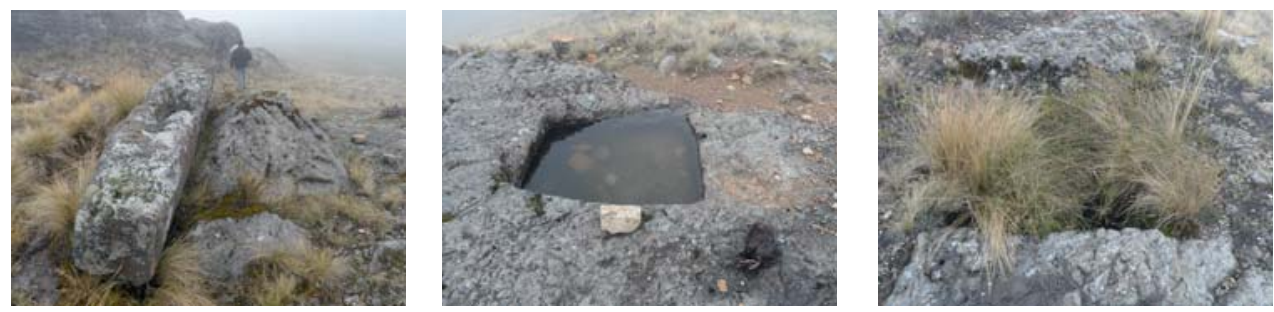

Figuras 16, 17 y 18: Piedras megalíticas y tumbas disturbadas dispuestas en las cercanías de la E7.

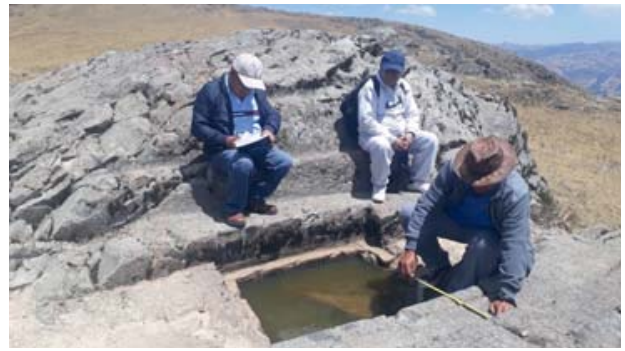

Figura 19: Poblador de Cachicadán, apoyando en sacar medidas de la estructura funeraria conocido también como "pocito encantador" de Huallío.

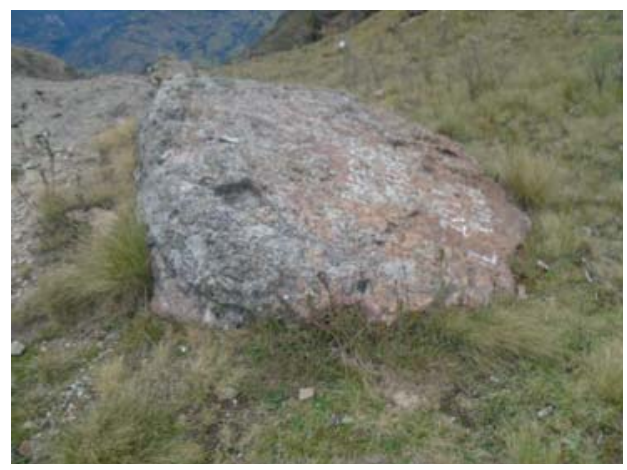

Figura 21: Bloque de piedra labrada de $3.50 \mathrm{~m}$ de largo, formaba la tapaba la tumba o E7.

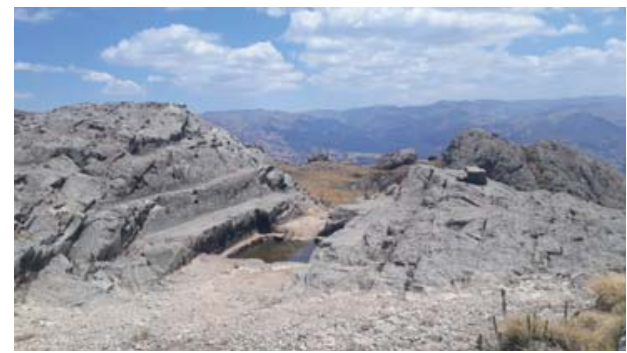

Figura 20: Detalle de la estructura labrada, donde se aprecia la sección escalonada. En segundo plano la estructura 6.

E7. Tumba disturbada (Coordenadas UTM: 818373E/9104953N), $2889 \mathrm{msnm}$, a 60-70 $\mathrm{m}$ al oeste de la E6. Presenta forma cuadrangular, mide 96 $\mathrm{cm}$ y $1 \mathrm{~m}$ en los lados sur y norte por 99 y 94 en los lados oeste y este, la tapa que la cubría se encuentra a $4 \mathrm{~m}$ al noroeste, y consiste en un bloque de piedra megalítico cuyas medidas encajan con el ancho de la tumba de forma cuadrangular, labrada en la saliente del afloramiento rocoso, la cual al ser despojada de su contenido quedó convertida en pozo
ran la estructura funeraria tipo mausoleo conforme se observa en las fotos que ilustran la estructura funeraria tipo mausoleo con graderías talladas en la misma saliente de aparente uso ceremonial. Comenta la gente del lugar, que, de esta pocita salió una serpiente, que elevándose por los cielos, en medio de granizo, neblina y estruendos se dirigió hacia el norte, posiblemente hacia la laguna Huaylillas, en las cercanías del Catequil, dios todopoderoso de la región norte. Otros cuentan que una pastora quedó encantada al tratar de coger una fruta que salía de una planta de naranja que había crecido en medio del pozo, es por eso que en la actualidad los pastores tratan de no llegar por la pocita. 


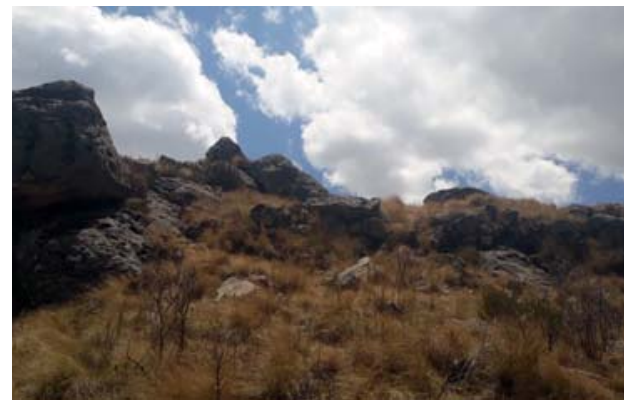

Figura 22: Muro de contención que delimita el lado oeste de la peña con el mausoleo megalítico.

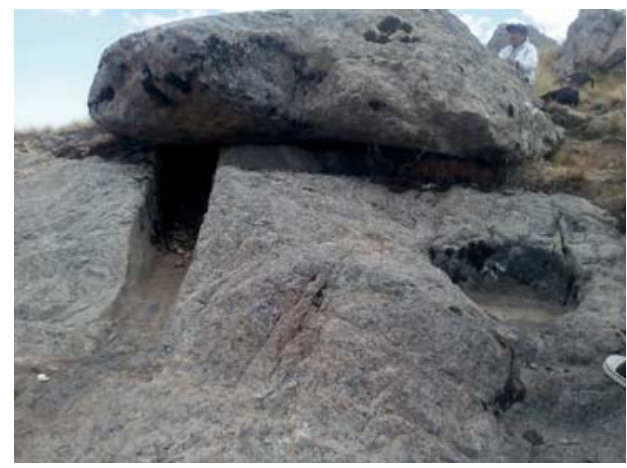

Figura 24: Detalle del bloque de piedra que sirve de tapa de la tumba con canal y pocito ceremonial tallado en afloramiento rocoso.

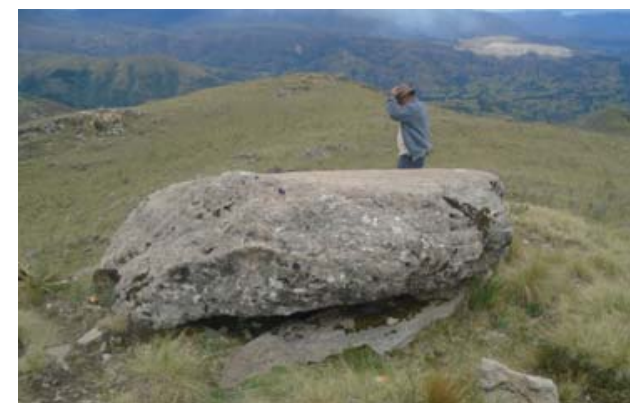

Figura 23: Bloque de piedra de $2.60 \mathrm{~m}$ de largo por $80 \mathrm{~cm}$ de grosor, que cubre al mausoleo megalítico.

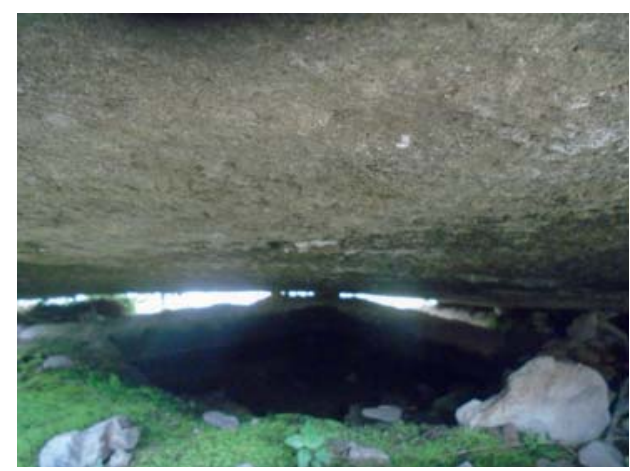

Figura 25: Interior del mausoleo saqueado, convertido en pozo de agua, conocido como pocita de Huallio.

E8. Mausoleo megalítico (Coordenadas UTM: 818384E/9105005N, 3898 msnm.), localizado aproximadamente a $30 \mathrm{~m}$ al noroeste de la E7, sobre una peña a la que se accede cruzando un muro de contención que delimita la parte superior de la peña, donde encuentra un bloque de piedra de $3.50 \mathrm{~m}$ de largo por $2.80 \mathrm{~m}$ de ancho y $90 \mathrm{~cm}$ de espesor, forma la tapa de la tumba de forma cuadrangular, excavada en la roca basáltica de misma peña: Lamentablemente saqueada y convertida en pozo agua tal como se observa en la actualidad. Conserva la forma original, excepto la tapa que aparece ligeramente levantada por efectos del saqueo. La estructura funeraria aparece asociada a una canaleta que la circunda para luego terminar en un canal de $45 \mathrm{~cm}$ de profundidad por $32 \mathrm{~cm}$ de ancho, en el ángulo noreste y en el ángulo sureste exterior existe un pozo circular del $60 \mathrm{~cm}$ de diámetro. El área que ocupa el mausoleo está en más del 60\% erosionado aparece la superficie de la peña y en la otra parte una delgada capa de tierra contiene abundantes fragmentos de piedra pizarra, material que no es propio del lugar, fue quizá traído para fines ceremoniales. Este tipo de estructura megalítica tiene parecido a las estructuras registradas por Julio C. Tello en la expedición al marañón, quien ilustra con un dibujo a la estructura registrada en Yanacancha, Ca- 


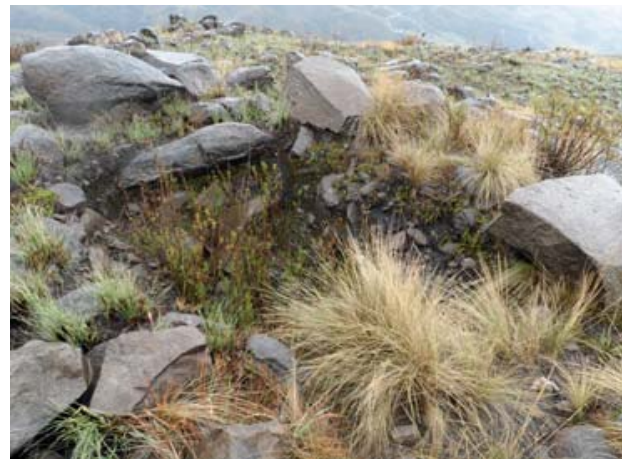

Figura 26: Detalle de la estructura funeraria E9, en el extremo oeste de la loma de donde se observa el poblado de Chiragbal.

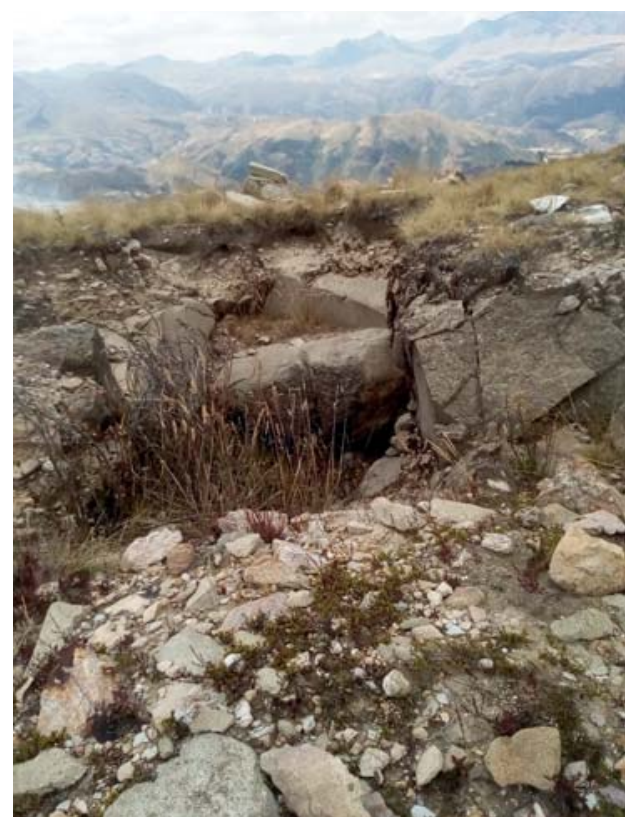

Figura 27: Detalle de la E10, donde se aprecia el área disturbada y afloramiento donde estuvo ubicada la estructura funeraria, en el extremo este de la loma.

jamarca. La comparación entre ambas estructuras aparece descrita en el libro Patrimonio Cultural del Perú, Monumentos arqueológicos de Santiago de Chuco, La Libertad, por Pérez (2012: 117).

E9 y E10.Tumbas disturbadas (Coordenadas UTM: 818477E /9105019N-818438E/9105042N), 3891 msnm. Localizadas a $50 \mathrm{~m}$ al noroeste de la E8, sobre una loma, las estructuras o tumbas huaqueadas ocupan los extremos de la loma separadas por una distancia aproximada de 30-35 m. se observa piedras sueltas de la estructura funeraria en el todo el espacio disturbado, no existe restos óseos tampoco fragmentos de cerámica.

\section{E11.Huancas (Coordena-} das UTM: $818594 \mathrm{E} / 9105057 \mathrm{~N}), 3870$ msnm, localizadas a $100 \mathrm{~m}$ al noroeste de la E9, desde donde se desciende hasta llegar a un conjunto de piedras dispersas junto a los restos de un antiguo camino, destacando 6 grandes bloques alargados de piedra, tres de los cuales están parados, de estos, el mayor mide $3.25 \mathrm{~m}$ de alto por $1.30 \mathrm{~m}$ de ancho, junto otros que aparecen caídos, uno de estas últimas tiene apariencia de un dintel, razón por la los pobladores del lugar la denominan "portada del sol", pero en realidad se trata de un conjunto de huancas, indicadoras de un espacio ceremonial de función específica aún no determinada.

E12. Plataforma ceremonial (Coordenadas UTM: 818909E/9104902N), $3740 \mathrm{msnm}$., estructura construida junto al camino de entrada al poblado de Chiragbal. Presenta forma rectangular con eje rectangular norte-sur, de lo que solo se aprecia el ángulo sureste en una extensión de 8 a $10 \mathrm{~m}$ por lado cuya proyección llega aproximadamente a $30 \mathrm{~m}$ de largo por $15 \mathrm{~m}$ de ancho, con altura visible de $1.20 \mathrm{~m}$. Hacia los lados norte y oeste se conecta a otros espacios abiertos dispuestos a distintos niveles a modo de plazas. 


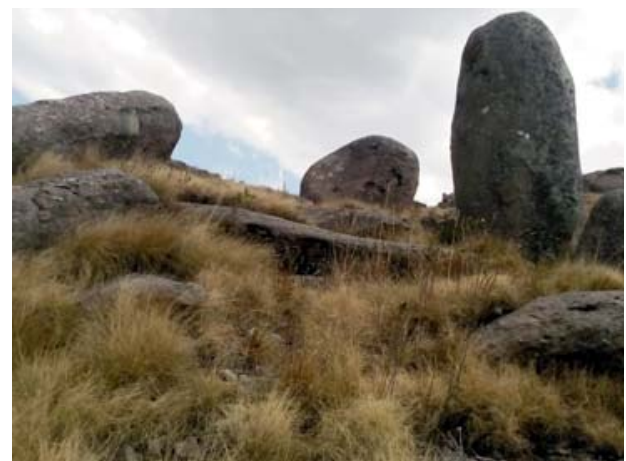

Figura 28: Bloques alargados de piedras dispuestas a manera de portada

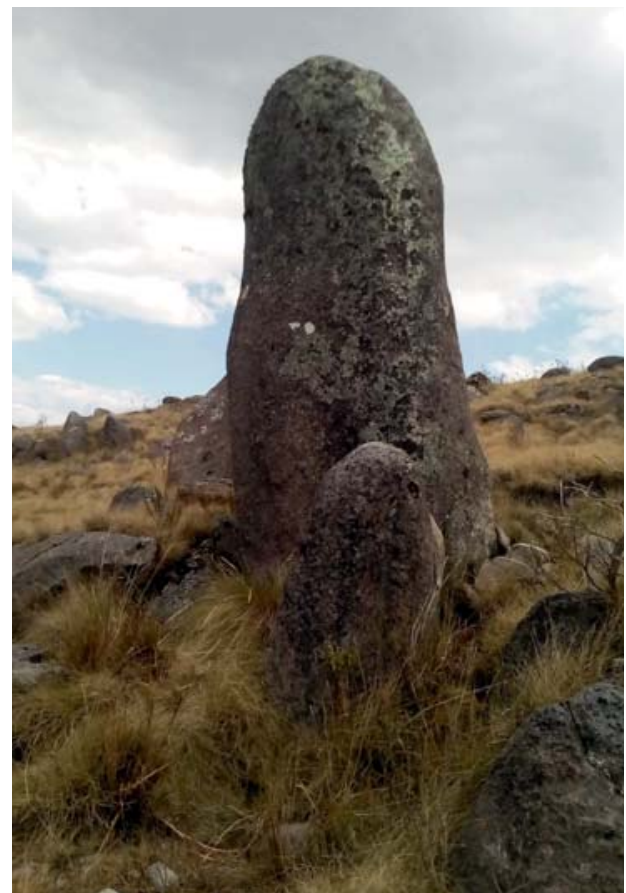

Figura 29: Detalle de dos huancas paradas junto a camino antiguo

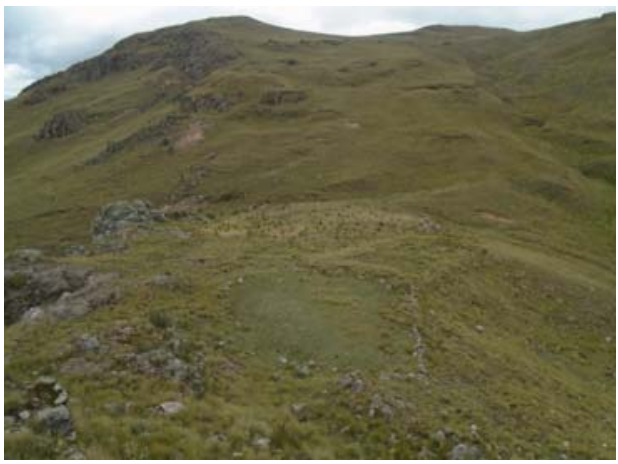

Figura 30: Vista de la plataforma asociada a otros espacios abiertos, al fondo ladera con estructuras desde la E14 hasta la E29.

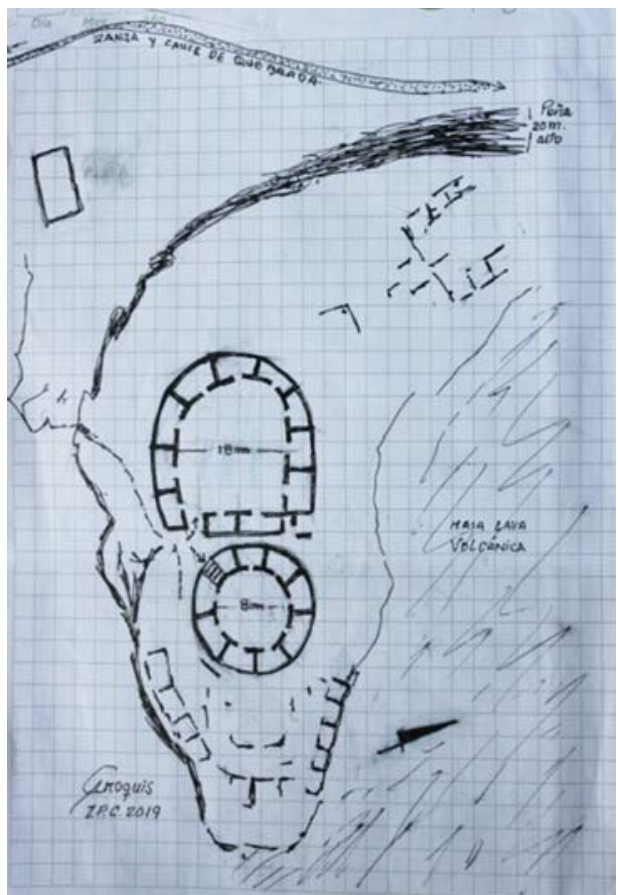

Figura 31: Croquis parcial del conjunto arquitectónico del cerro Chiragbal (Dib: IPC, 2020).

E13. Poblado de Chiragbal (Coordenadas UTM: 818983E/9104935N), $3787 \mathrm{msnm}$. El nombre del lugar proviene de, topónimo Shirac (término en lengua culle) que corresponde a una planta de fruto amargo que existe en el lugar. Se accede por la plataforma o E12, luego de cruzar una zanja defensiva que da origen a dos quebradas que discurren hacia los lados oeste y este del cerro, siguiendo un camino que llega hasta el lado sur de la peña, donde existe una sola entrada, angosta y em- 


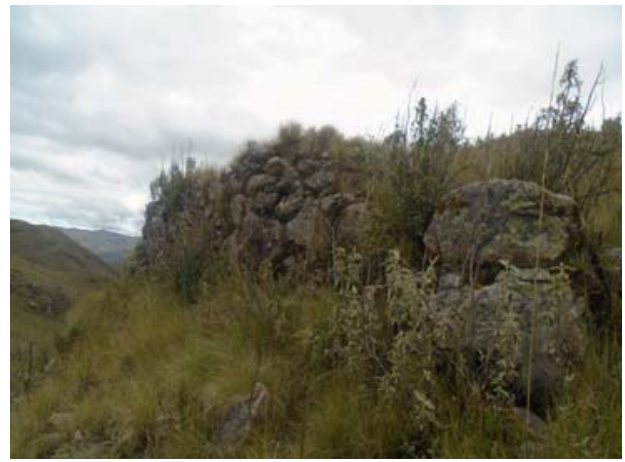

Figura 32: Muro de contención de la segunda plataforma habitacional del poblado de Chiragbal.

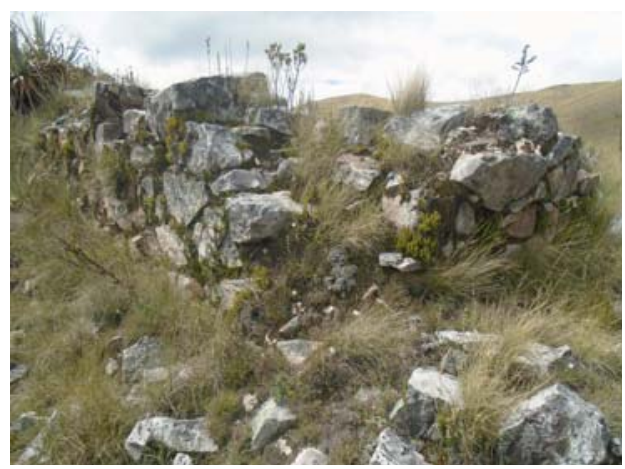

Figura 34: Esquina de un recinto rectangular en el lado este del poblado de Chiragbal.

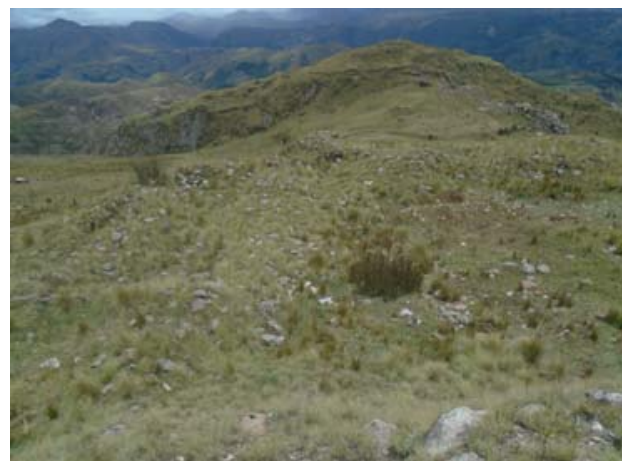

Figura 36: E14. Restos de arquitectura ortogonal de probable influencia Wari.

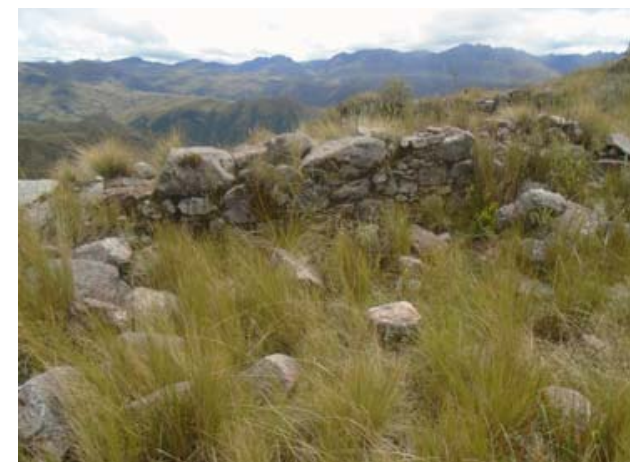

Figura 33: Detalle de la pared interna de un reciento en la cima del poblado de Chiragbal

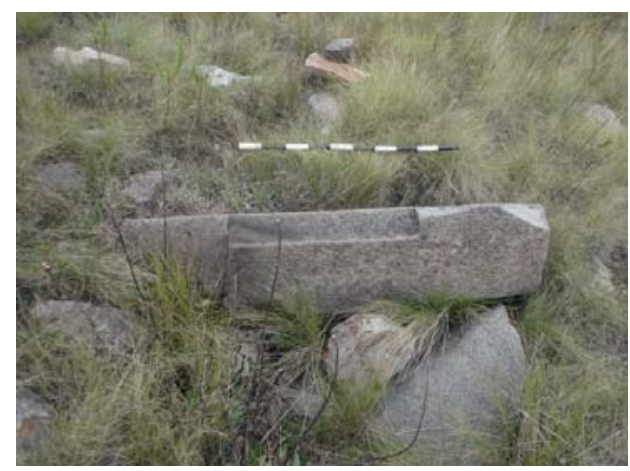

Figura 35: Detalle de piedra tallada en forma de fuente de agua de $70 \mathrm{~cm}$ de largo, con sección transversal en " $V$ ".

pedrada que conecta a un "callejón" en la terraza inferior para luego subir a la segunda y tercera terraza con estructuras habitacionales del antiguo poblado que se extiende en la cúspide del cerro Chiragbal, el cual es inaccesible por las altas peñas de los lados este y oeste, así como por el lado norte formado por una ladera plana y empinada dispuesta a modo de una gigantesca meza de origen volcánico.

El poblado preincaico de Chiragbal, aparece constituido por lo menos de 5 unidades habitacionales con viviendas distribuidas alrededor de patios dispuestos en diferentes niveles (el patio del nivel superior mide 9- $8.50 \mathrm{~m}$ de diámetro),conectados con graderías, pasadizos. 

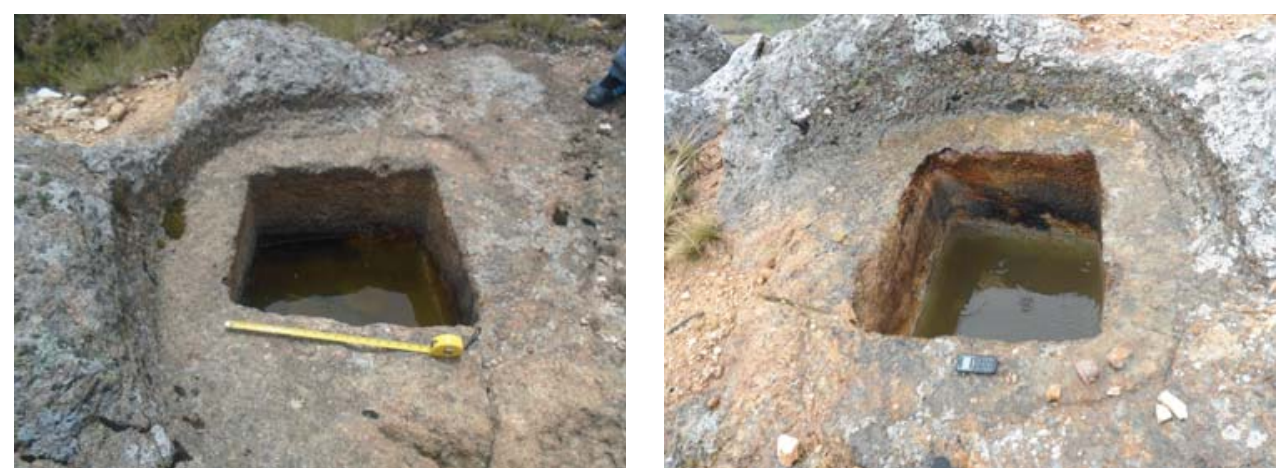

Figuras 37 y 38: Forma y tamaño de la estructura funeraria tallada en la propia roca, disturbada en la época colonial y convertida en la actualidad en pozo de agua.

Los recintos son de forma cuadrangular, rectangular y trapezoidal con ángulos internos curvos con accesos orientados a los patios; los muros conservan alturas como para techos de una sola planta. Se observa adosamientos y superposición de estructuras producto de una prolongada ocupación cultural atribuida al primer milenio y primera mitad del segundo milenio después de Cristo.

E14. Arquitectura ortogonal (Coordenadas UTM: 18739E/

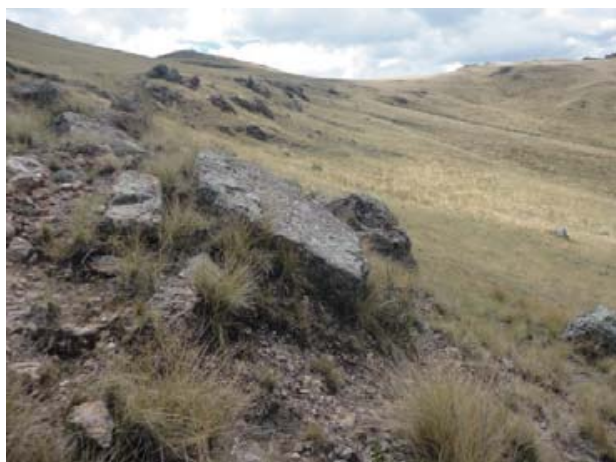

Figura 39: Bloques de piedra tipo lozas, utilizados como tapas de tumbas. $9104822 \mathrm{~N}), 3820 \mathrm{msnm}$ dista aproximadamente $100 \mathrm{~m}$ al sureste de la plataforma o E12, consiste en cabeceras de un conjunto de estructuras cuadrangulares, rectangulares y circulares bien planificadas, trazadas y construidas en la ladera oeste del cerro Huallio que conecta con el cerro Chiragbal. Una de las estructuras abierta que parece corresponder a un patio mide $30 \times 20 \mathrm{~m}$, de terreno plano previamente nivelado, alrededor del cual existen otros recintos cuadrangulares de menor tamaño, propios del patrón arquitectónico Wari. Los recintos circulares están cerca del lecho de antiguas lagunas, existen muros de contención que forman distintas terrazas, el conjunto arquitectónico aparece enterrado en una extensión aproximada de 4 has, cortadas por el cauce temporal de quebradas que discurre de sureste a noroeste. Los restos arquitectónicos forman parte de un viejo asentamiento que antecedió al centro poblado prehispánico de Chiragbal. Época a la que se atribuye el patrón de enterramiento en cámaras megalíticas, talladas en bloques y afloramientos rocosos.

E15. Estructura disturbada (Coordenadas UTM: 818756E/910700N), 3816 msnm, corresponde a la matriz de forma trapezoidal de una tumba excavada en afloramiento rocoso, borde de la ladera oeste del Huallio. La estructura presenta en 

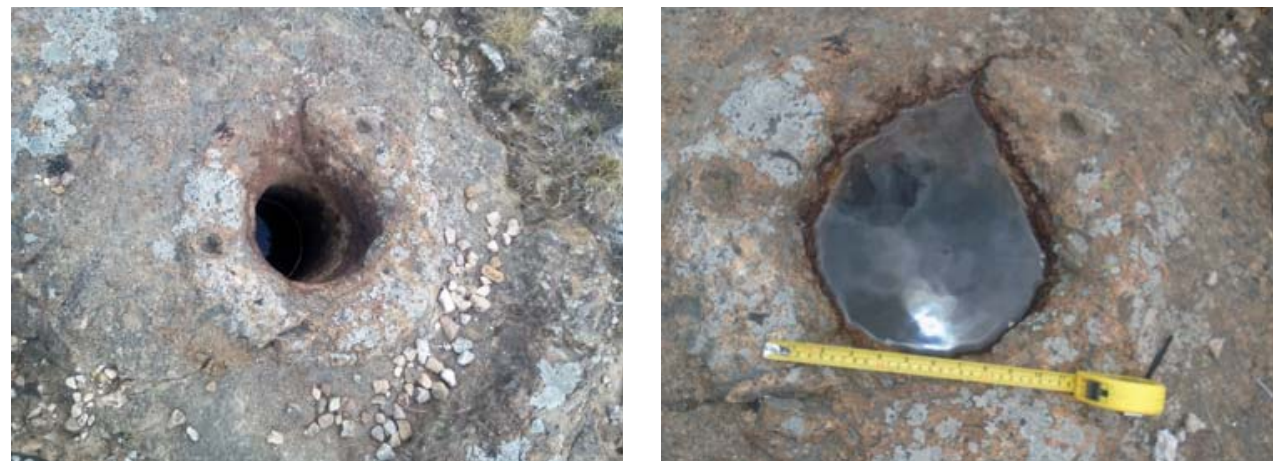

Figuras 40 y 41: Detalle de la cavidad circular con el borde y cuerpo que aparenta corresponder a una serpiente, que coincide con la leyenda que comentan los pobladores del lugar.
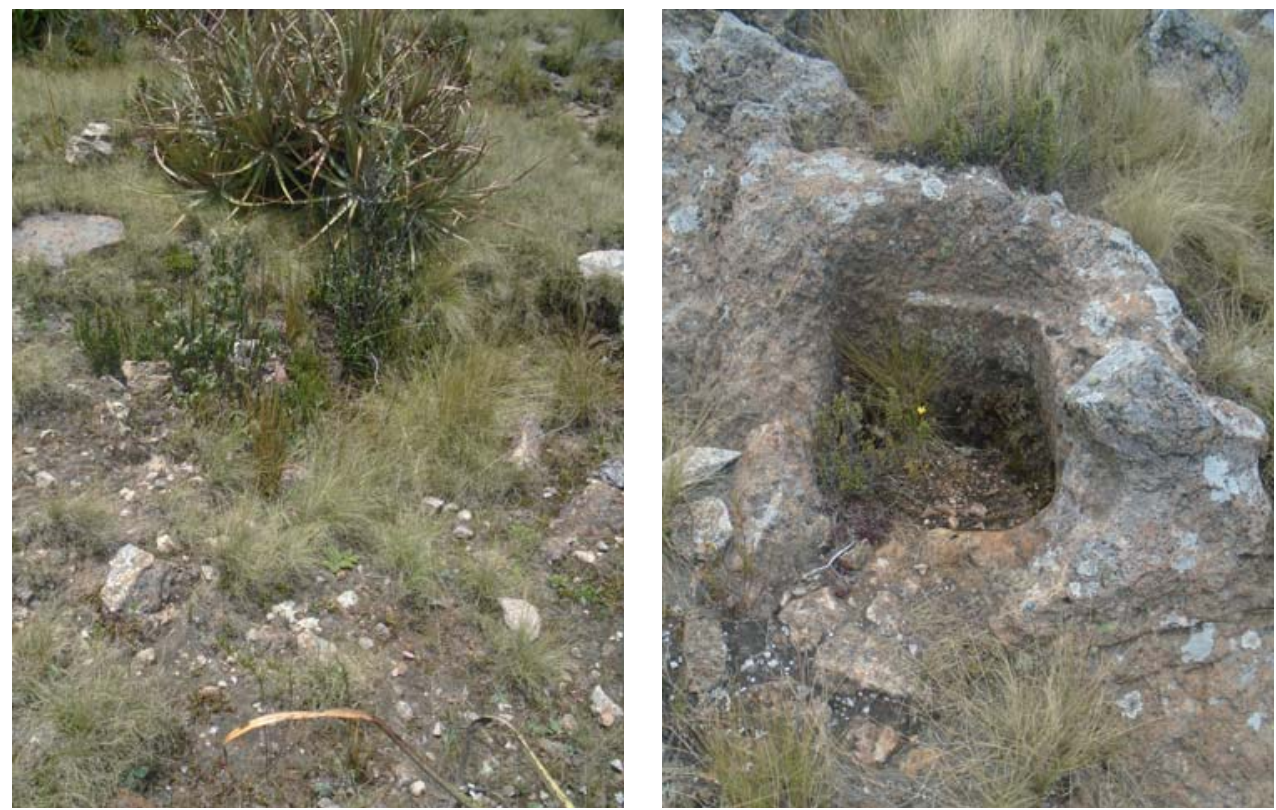

Figuras 42 y 43: Detalle de estructuras funerarias disturbadas, cercanos a la cavidad circular

reborde en forma de "U" con el espacio abierto orientado hacia el este, tiene $72 \mathrm{~cm}$ de profundidad visible, los lados norte y sur 38 y $64 \mathrm{~cm}$ y los lados este y oeste 64 y $36 \mathrm{~cm}$ respectivamente, borde en ángulo de $45^{\circ}$ y $20 \mathrm{~cm}$ de ancho con talladura como para ensamblar a la tapa o loza megalítica. La superficie expuesta a la intemperie está cubierta de líquenes y musgo.

E16. Estructura disturbada (Coordenadas UTM: $818748 \mathrm{E} / 9104689 \mathrm{~N}$ ), $3812 \mathrm{msnm}$., $20 \mathrm{~m}$ al sur de la E1. Presenta forma circular, mide $26 \mathrm{~cm}$ de diámetro por $40 \mathrm{~cm}$ de profundidad visible, borde en relieve, da la apariencia de corresponder al cuerpo de una serpiente con la cabeza aparece expuesta en el borde de la 

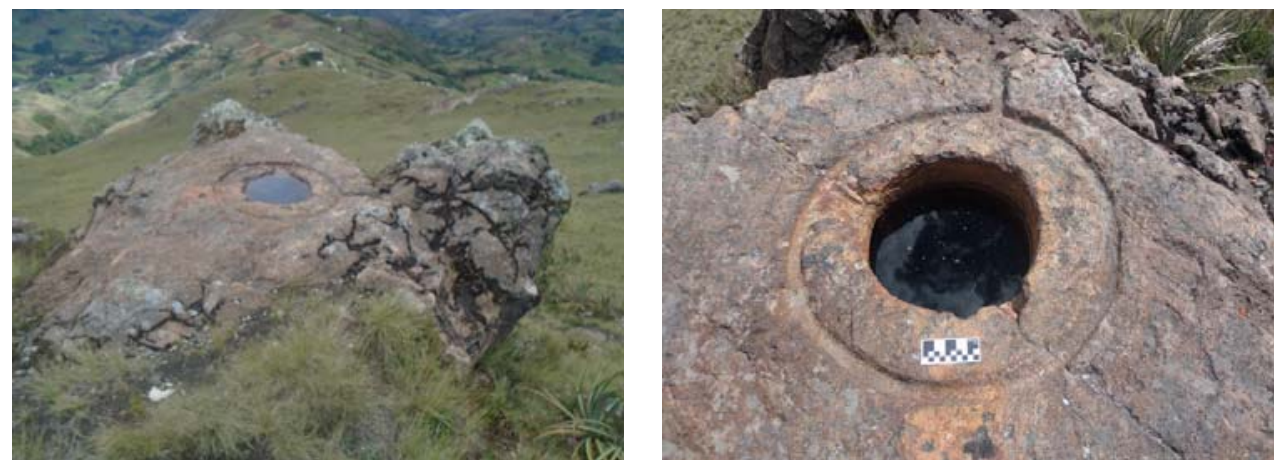

Figuras 44 y 45: Panorámica de la forma de la roca y detalle de la cavidad funeraria disturbada.

cavidad circular, cuerpo enroscado y la cola proyectada hacia el interior. De ser así estaríamos frente a la representación de la leyenda que narra que de una del cerro Huallio, salió una serpiente entre los estruendos, rayos y granizo, elevándose entre el cielo para dirigirse a la laguna Huaylillas, en la vecina provincia de Huamachuco.

E17. Estructura circular disturbada (Coordenadas UTM:818761E/ $9104687 \mathrm{~N}), 3817 \mathrm{msnm}$, localizada a 15 $\mathrm{m}$ al oeste de la E16, corresponde a la matriz de una tumba, la cavidad circular mide $40 \mathrm{~cm}$ de diámetro, por $70 \mathrm{~cm}$ de profundidad, presenta canaleta vertical la pared del lado oeste, el borde aparece delimitado por un circulo en relieve de 10-12 $\mathrm{cm}$ de ancho, uno de los extremo termina también en una cabeza de serpiente, con el cuerpo introduce al interior, dando as-

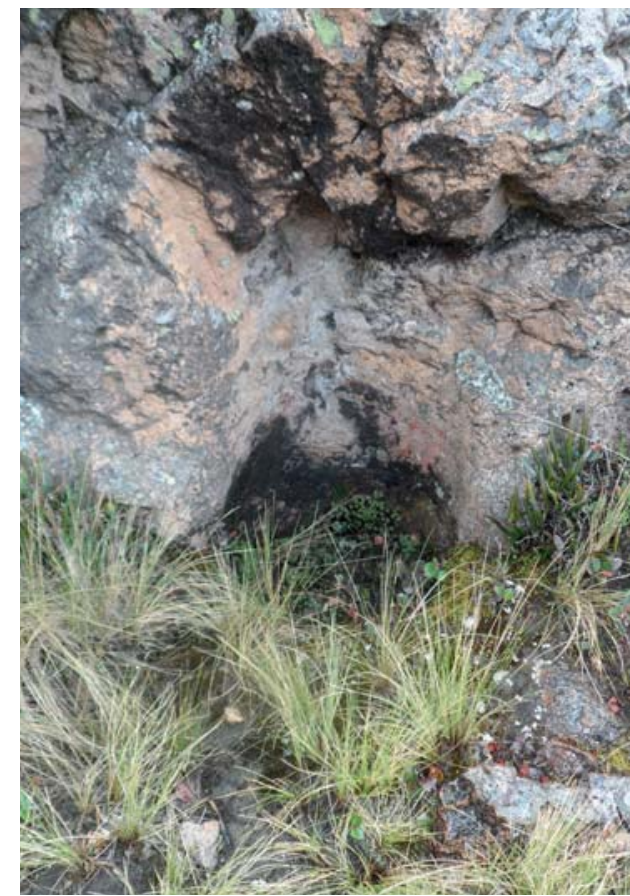

Figura 46: Detalle de la ventanilla cubierta de ichu. pecto de estar enrollada y circundada por una canaleta con salida hacia el lado sur para drenar el agua cuando tenía la tapa que cubría a la estructura funeraria. La cavidad aparece trabajada en el centro de una roca, que viéndola desde el lado sureste aparenta la forma de un camélido (alpaca).

E18. Ventanilla (Coordenadas UTM: 818751E/9104683N), $3818 \mathrm{msnm}$ localizada entre 6 a $8 \mathrm{~m}$ al suroeste de la E16. La ventanilla aparece cubierta por ichu en la parte inferior de la peña, corresponde al parecer a una estructura funeraria disturbada. 

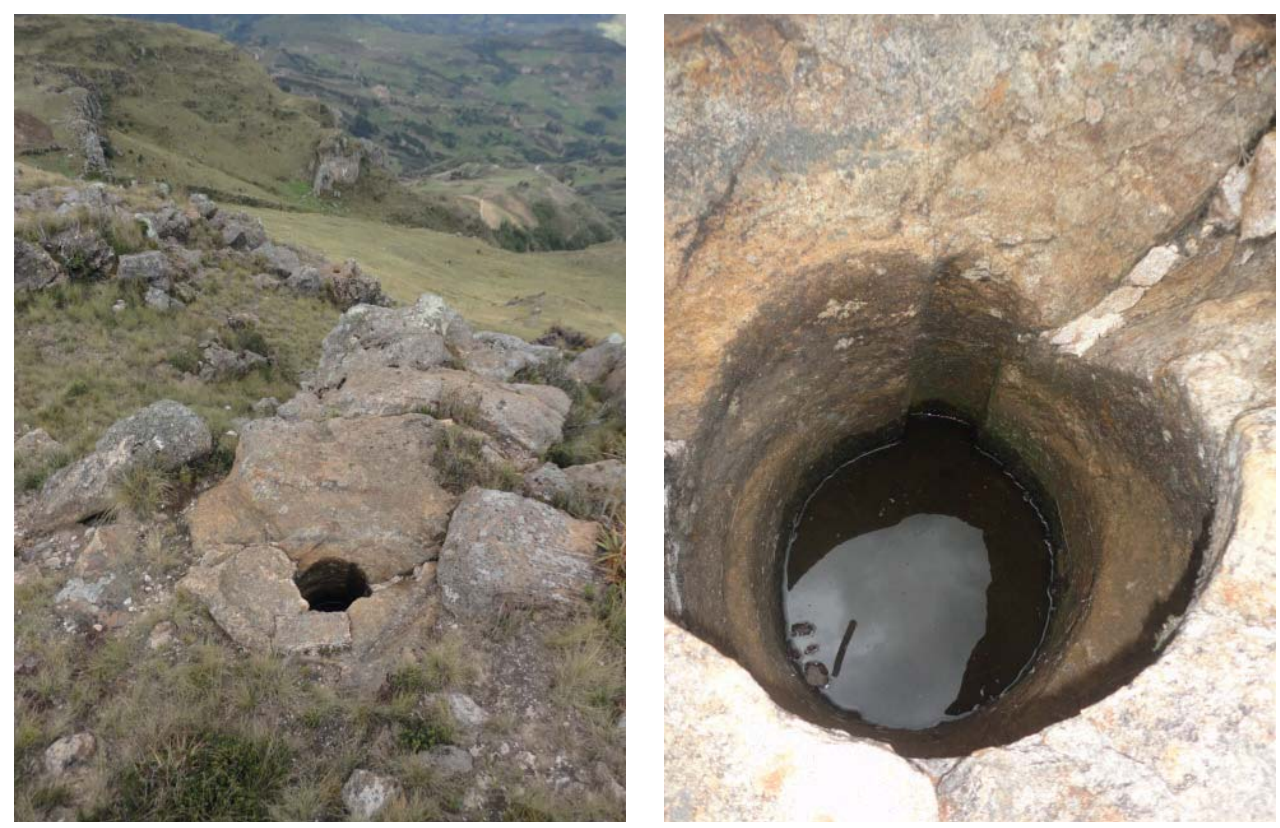

Figuras 47 y 48: Vista general de la estructura y detalle de la canaleta vertical.

E19. Estructura funeraria disturbada (Coordenadas UTM: 818736E/ $91046700 \mathrm{~N}), 3866 \mathrm{msnm}$, a $25-30 \mathrm{~m}$ al sur de la E16. Tal como se percibe presenta problemas de erosión con resquebrajamiento natural de la misma roca. Tiene forma circular de $50 \mathrm{~cm}$ de diámetro por $67 \mathrm{~cm}$ de profundidad, con borde ensanchado delimitado por una canaleta que la circunda para drenar el agua. La diferencia es la canaleta vertical al interior de la cavidad, la cual debió servir para escurrir líquido como parte de los ritos y ceremonias posmorten, rasgo arquitectónico común en la arquitectura megalítica funeraria expuesta la ciudad de Wari, Ayacucho.

E20. Estructura funeraria disturbada (Coordenadas UTM: 818718E/ $9104656 \mathrm{~N}), 3822 \mathrm{msnm}$. Ubicada a $20 \mathrm{~m}$ al sur de la E19, presenta forma cuadrangular con borde en relieve en forma de " $U$ " abierta hacia el lado norte, mide 82-92 $\mathrm{cm}$ en los lados sur y norte, mientras que los lados este y oeste miden 1.04-1.03 $\mathrm{cm}$ respectivamente por $70 \mathrm{~cm}$ de profundidad expuesta, el ancho del borde es de 17 a $20 \mathrm{~cm}$, forma una grada de $35 \mathrm{~cm}$ de alto. Presenta erosión natural de la roca de origen volcánico. En el afloramiento rocoso cerca de esta estructura existe una pequeña ventanilla o nicho del estilo Cajamarca. De igual manera hacia el lado este en la ladera del cerro existen otras estructuras como lozas que formaban tapa de las tumbas y cavidades cuadrangulares de carácter funerario disturbadas.

E21. Estructura funeraria disturbada (Coordenadas UTM: 818700E/ $9104642 \mathrm{~N}), 3831 \mathrm{msnm}$, tallado en afloramiento rocoso de tufo volcánico, presenta forma cuadrangular con borde en relieve en forma de "U", abierto hacia el lado oes- 

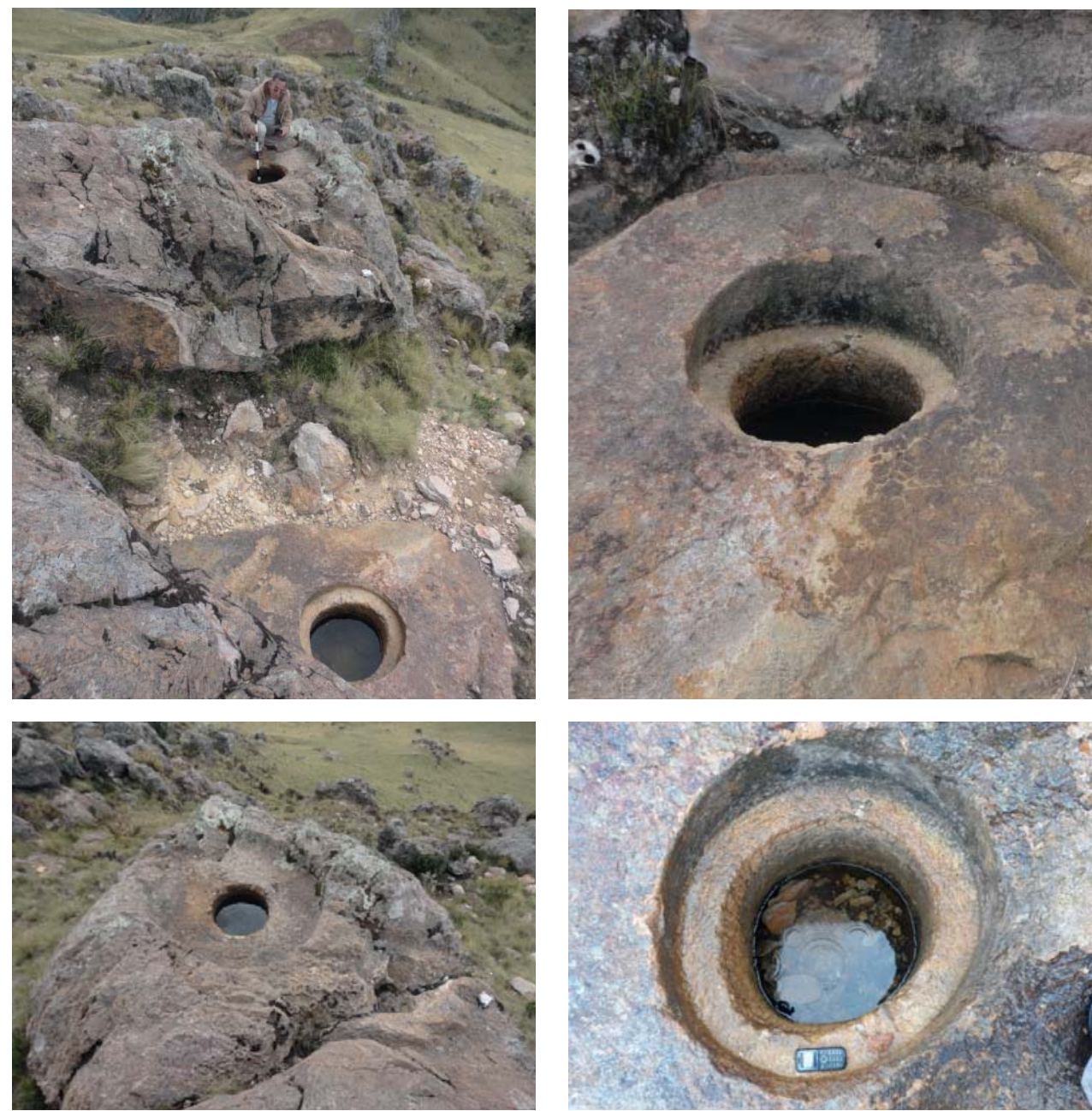

Figuras 49, 50, 51 y 52: Vista de otras dos estructuras funerarias profanadas, ambas tenían tapa megalítica, una con canaleta de drenaje alterada por la mano del hombre actual.

te, hacia el lado opuesto y sobre el mismo afloramiento rocoso aparece una piedra rectangular tallada en forma de " $U$ " en bajo relieve en la parte central del bloque megalítico, que corresponde a la tapa de la tumba, debido a que dimensión de la parte tallada encaja con el borde en relieve la estructura funeraria cuadrangular expuesta con agua, que mide $40 \times 50 \mathrm{~cm}$ por $50 \mathrm{~cm}$ de profundidad.

E22. Estructura funeraria (Coordenadas UTM: 818739E/9104613N), 3872 a $25 \mathrm{~m}$ al oeste de la E21, consiste restos de una tumba megalítica disturbada por buscadores de "tapados", se encuentra en la ladera oeste al pie del borde de la peña, pero un espacio donde al parecer existe otros entierros intactos.

E23. Estructura funeraria disturbada (Coordenadas UTM: $818748 \mathrm{E} /$ $9104609 \mathrm{~N}), 3909 \mathrm{msnm}$. Tiene forma cuadrangular con pozo circular al centro que 

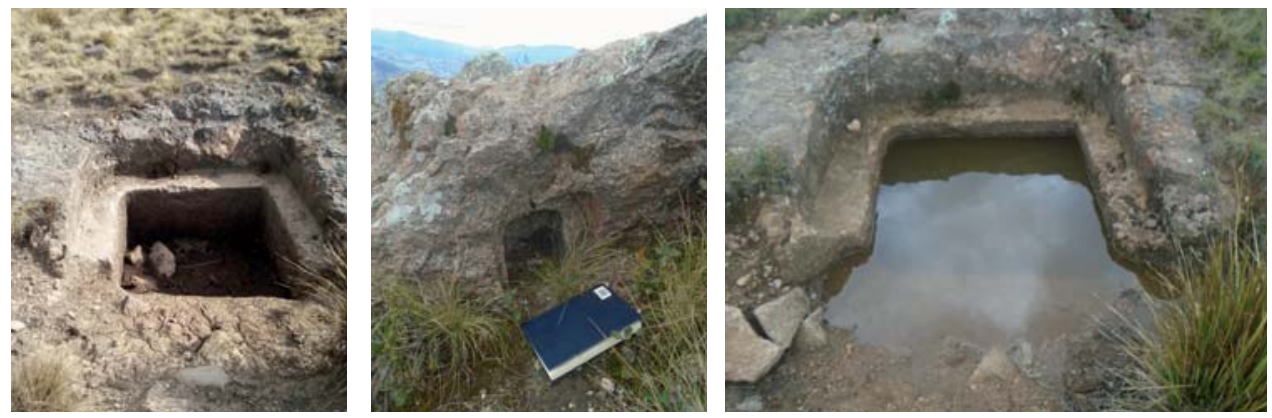

Figuras 53, 54 y 55: Matriz de estructura funeraria en tiempo de verano e invierno y detalle de nicho de estilo Cajamarca cuyo tamaño se puede deducir si se toma en cuenta que la agenda mide $21 \mathrm{~cm}$ de largo por $14.5 \mathrm{~cm}$ de ancho.
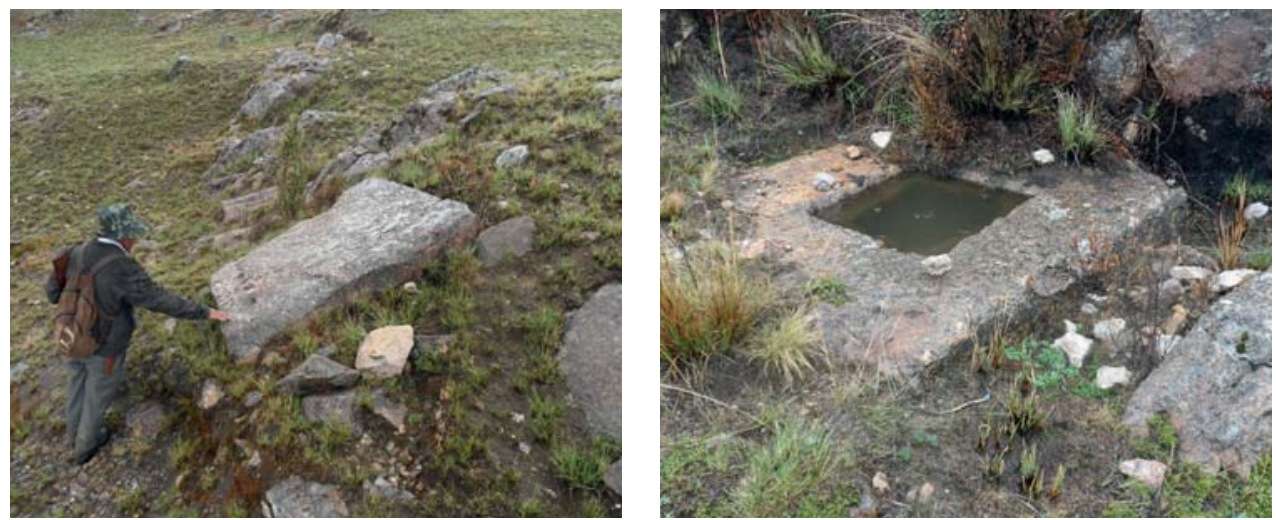

Figuras 56 y 57: Bloque labrado de piedra y estructura funeraria de forma cuadrangular disturbada.

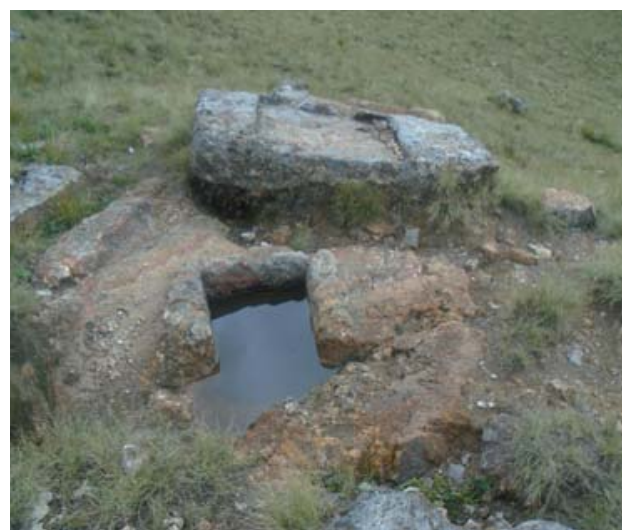

Figura 58: Estructura funeraria con sus respectivos Componentes arquitectónicos disturbados.

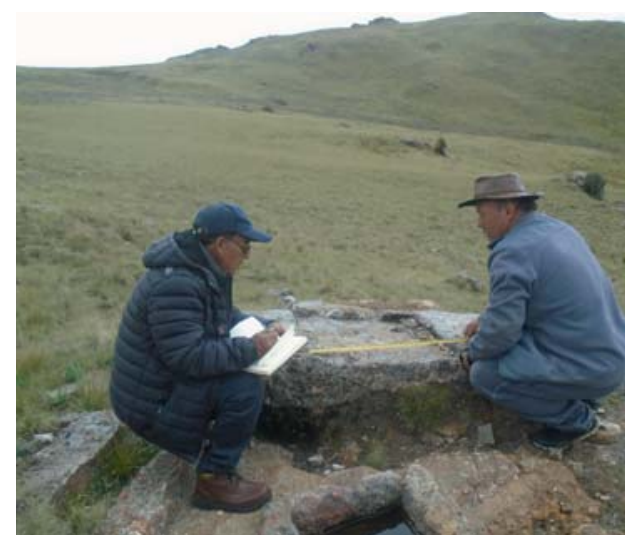

Figura 59: Autor del artículo con Antonio Vílchez en proceso de acumulación de datos. 


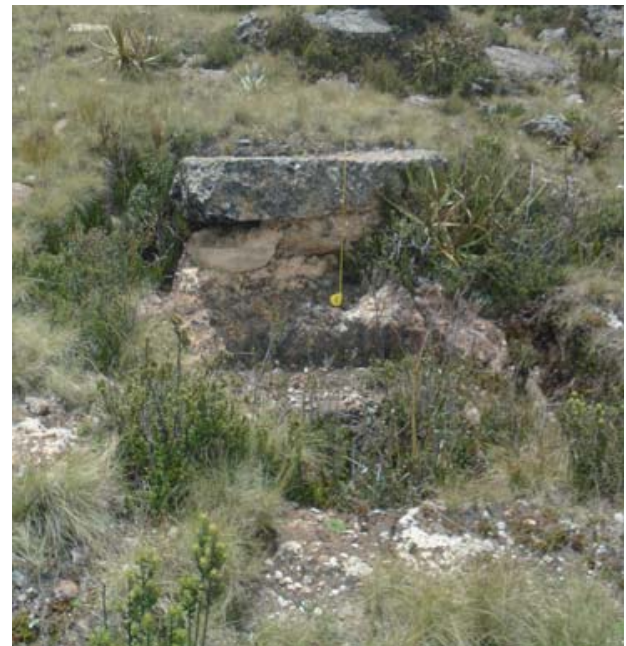

Figura 60: Perfil del área disturbada con la loza a nivel de superficie.

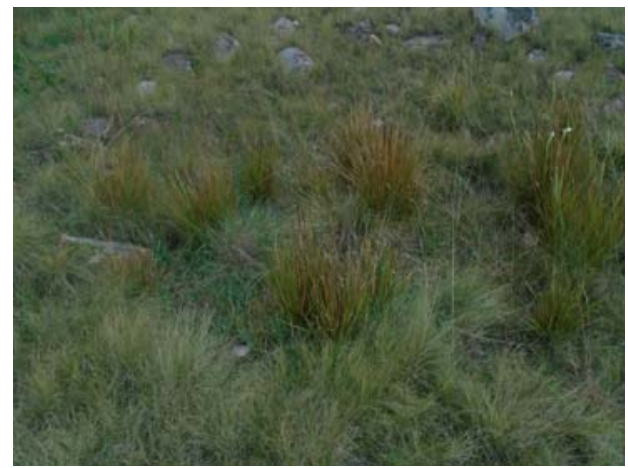

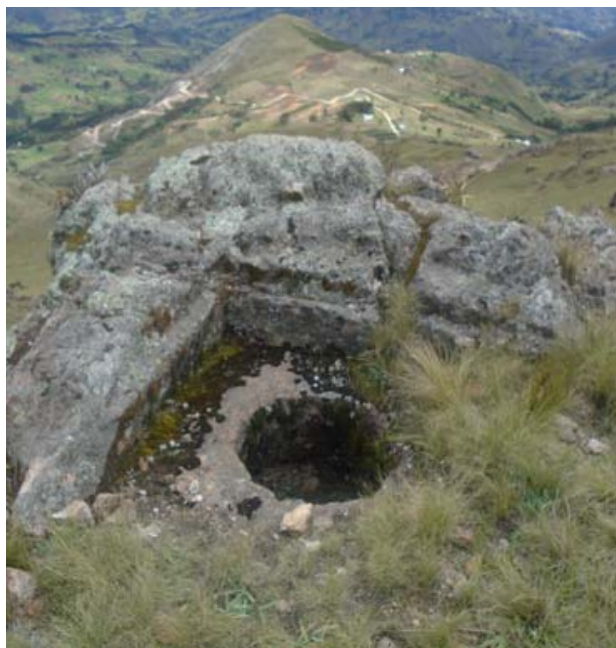

Figura 61: Estructura funeraria tallada en el borde la peña, al fondo cerro Caucallate.

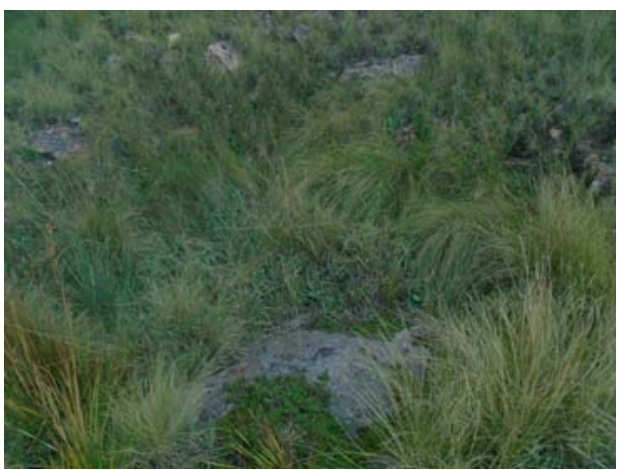

Figuras 62 y 63: Superficie hundida de posibles tumbas disturbadas.

bien a ser la matriz de la tumba tallada en el borde una saliente de la peña, en el lado que da hacia el cerro Caucallate, del que dista aproximadamente $1750 \mathrm{~m}$ en línea recta.

E24 y E25. Superficie hundida de estructuras funerarias disturbadas (Coordenadas UTM: $818674 \mathrm{E} / 9104593 \mathrm{~N}$ y $818661 \mathrm{E} / 9104576 \mathrm{~N}$ ), 3846-3852 msnm, aproximadamente a 50-60 metros hacia el sur de la E21. Se observa una hendidura que corresponde al centro de la posible estructura funeraria. La superficie carece de cerámica y restos óseos.

E26. Cantera de cuarzo (Coordenadas UTM: 818648E/9104565N), 3858 msnm. Se ubica en toda la loma superior de la ladera oeste del Huallío, al pie de lo cual inicia áreas alteradas para el cultivo, con muros de contención de posibles estructuras habitacionales. El cuarzo aflora a nivel de superficie en pequeños peda- 


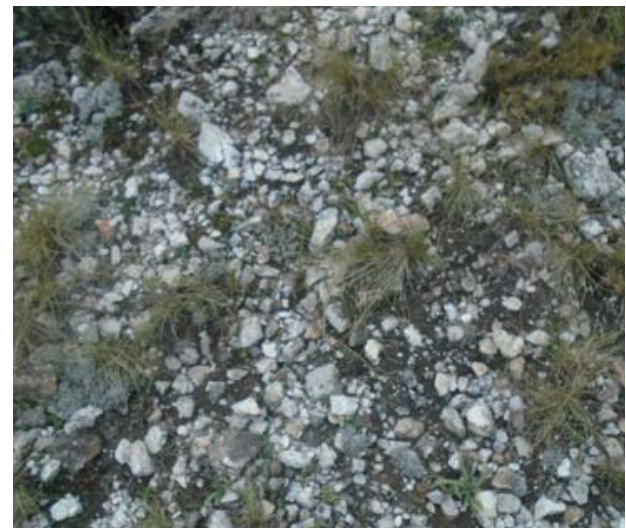

Figura 64: Superficie con afloramiento de cuarzo lechoso.

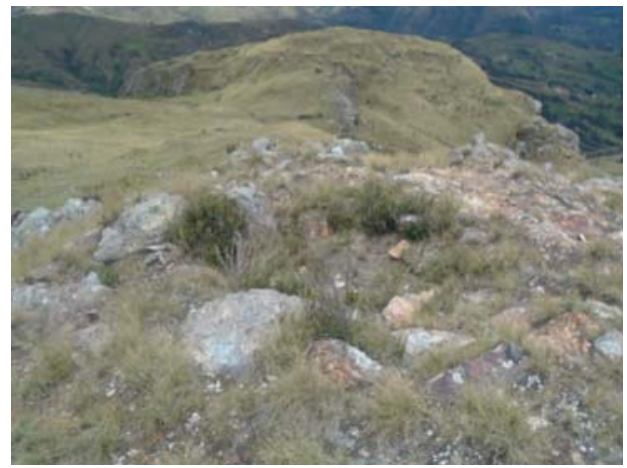

Figuras 66 y 67: Cabeceras de estructuras funerarias disturbadas dispuestas en la loma adyacente a la cantera de cuarzo, lado este del Huallio.

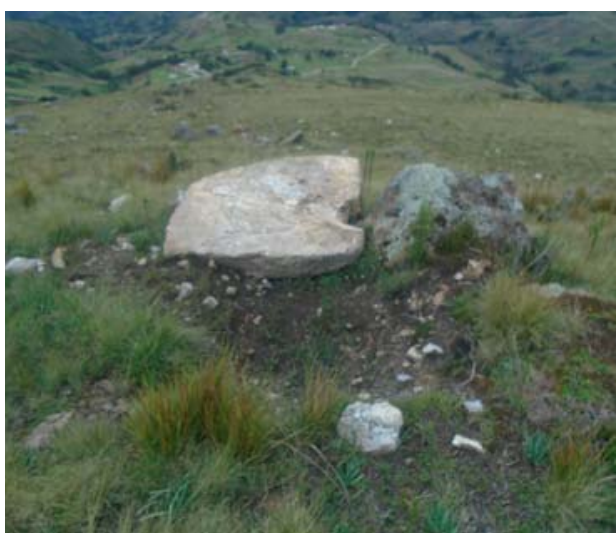

Figura 65: Tapa o loza con orificio, propia de las tumbas de la época Wari.

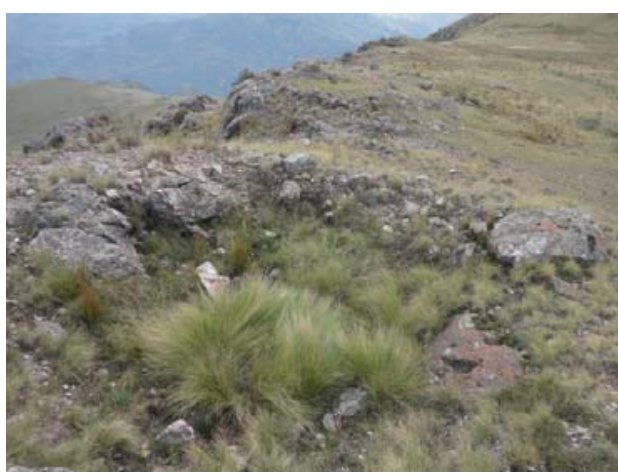
s zos, fácil de ser traslado o
aproximadamente $600 \mathrm{~m}^{2}$.

E27. Estructura disturbada (Coordenadas UTM: 818680E/9104521N), $3833 \mathrm{msnm}$. Corresponde a la tapa tipo loza de estructura funeraria. El elemento lítico es de granito presenta hoy en la mitad de uno de los bordes lo que implica que debió estar unida a otro bloque similar tamaño. Se encuentra fuera de su contexto y el área adjunta presenta actos de reciente remoción.

E28 y E29. Estructuras disturbadas dispuestas en la cima sureste del Huallio, cercanas a la Estructura 30 (Coordenadas UTM: 818591E/9104554N, $818570 \mathrm{E} / 9104550 \mathrm{~N}), 3871 \mathrm{msnm}$. Corresponde a piedras planas que formaban las tapas o paredes de posibles recintos funerarios.

E30. Estructura funeraria disturbada (Coordenadas UTM: 818544E/ $9104547 \mathrm{~N}), 3868 \mathrm{msnm}$. Los bloques megalíticos dispersos alrededor de un espacio hundido indican que formaban parte una estructura funeraria disturbada. 

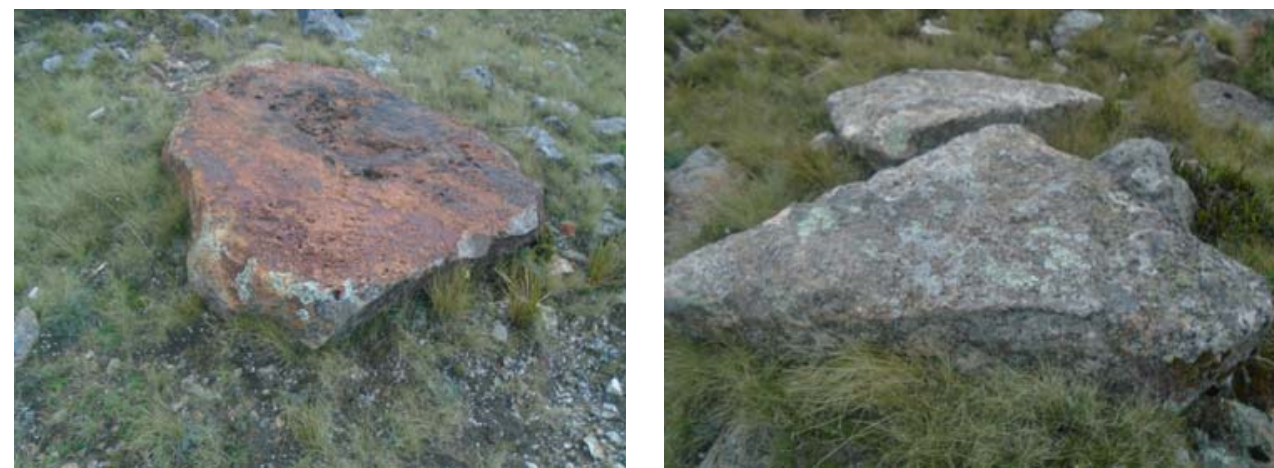

Figuras 68 y 69: Piedras planas disturbadas de contextos funerarios y expuestas en la superficie de la cima sureste del cerro Huallio.

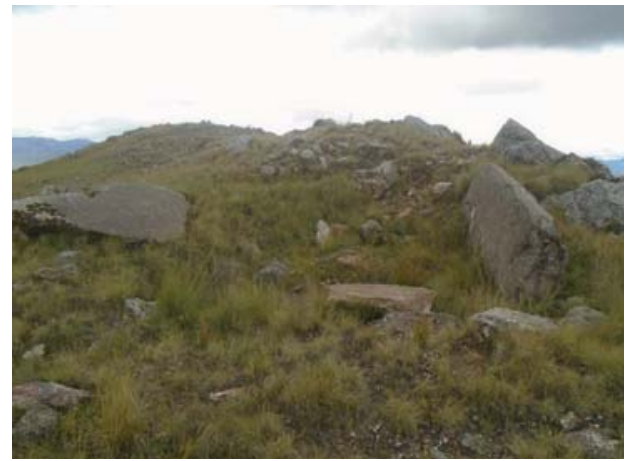

Figura 70: Bloque megalíticos dispersos producto de la alteración cultural del terreno

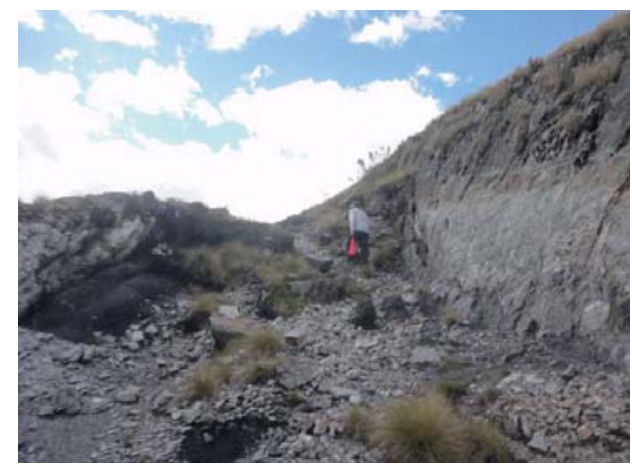

Figura 71: Perfil de mina de carbón de piedra en el borde sur.

E31. Betas de minas de carbón de piedra (Coordenadas UTM: $818330 \mathrm{E} / 9104611 \mathrm{~N}), 3795 \mathrm{msnm}$. En el borde sur del cerro Huallio, a $200 \mathrm{~m}$ aproximadamente de la E30. Corresponde betas carbón de piedra, algunas aprovechadas al parecer desde la época prehispánica. Los perfiles de las zanjas con carbón se profundizan y se extienden hacia el lado sureste del cerro, donde en la actualidad la minería informal viene explotando dicho recurso.

E32. Restos de poblado con recintos circulares (Coordenadas UTM: $818252 \mathrm{E} / 9104666 \mathrm{~N})$, en el lado este de la cima del cerro Huallio. Existen varias cabeceras de recintos circulares dispuestos de manera lineal de este a oeste en la divisoria del cerro cuyas aguas descienden a la jurisdicción de los distritos de Santa Cruz de Chuca y Cachicadán, para drenar a los ríos San Antonio y Huaychaca que separan del distrito de Santiago de Chuco.

E33. Estructura circular, (Coordenadas UTM: 818166E/9104779), 3745 $\mathrm{msnm}$. Ocupa el extremo este de la cima del cerro Huallio, hasta donde se extiende el poblado que tiene una extensión de aproximadamente $100 \mathrm{~m}$ de largo por 40 


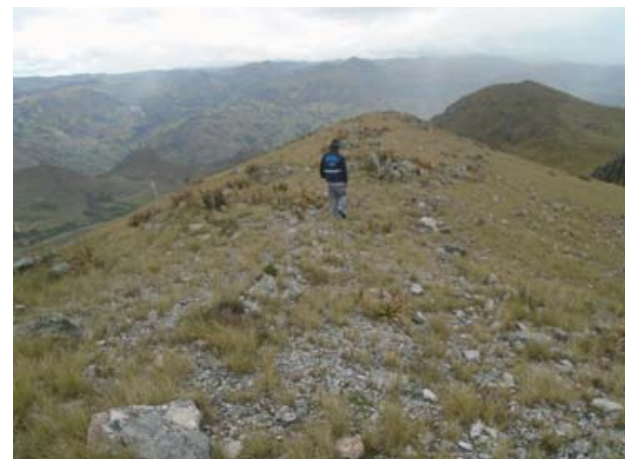

Figura 72: Cúspide del cerro Huallio con restos de estructuras habitacionales

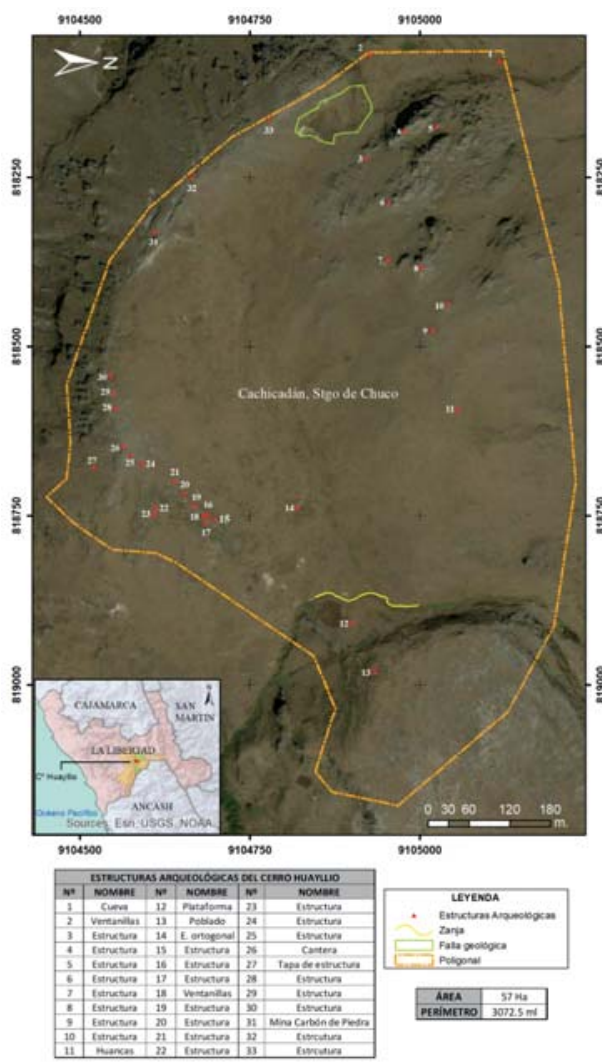

Figura 74: Ubicación de estructuras arqueológicas en foto satelital (Dib: David Pérez C.2019).

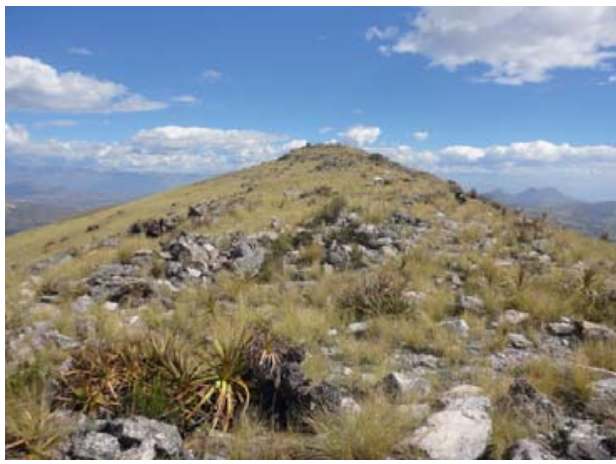

Figura 73: Recinto de forma circular en el extremo este, cima del cerro Huallio.

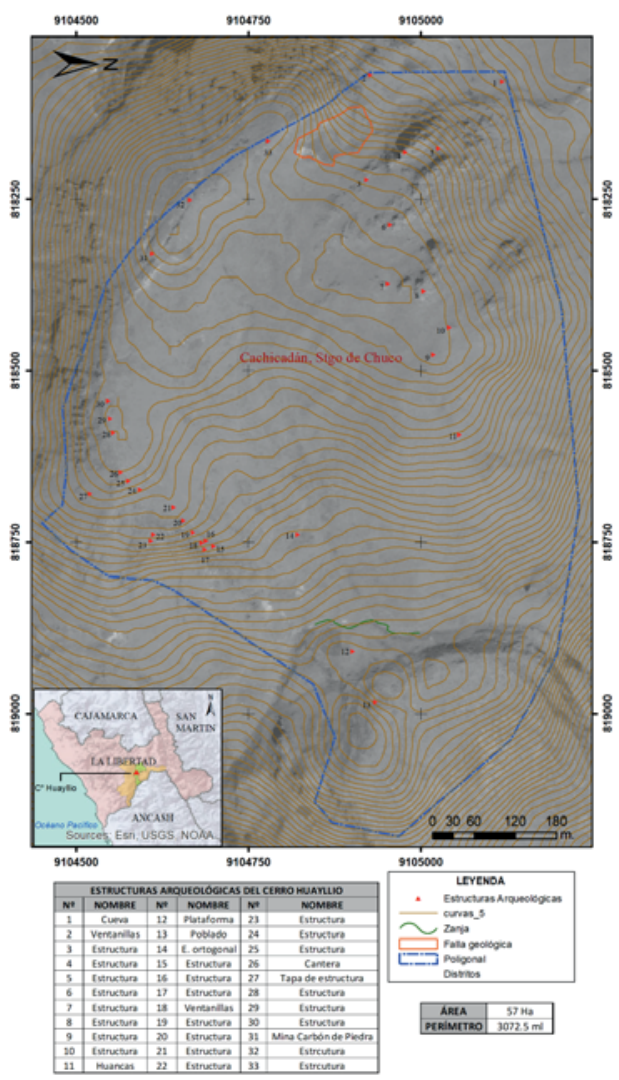

Figura 75: Ubicación de estructuras arqueológicas en plano topográfico (Dib: David Pérez C. 2019). 
$\mathrm{m}$ de ancho, es decir $4000 \mathrm{~m}^{2}$. Desde este punto se observa el valle de Santiago de Chuco con las huacas o santuarios prehispánicos de Yanahuanca e Ichal o Catequil y los distintos poblados establecidos en la cima de los cerros que rodean a la huaca o Huallio, descrita por los padres Agustinos (1918).

\section{Breve discusión}

Los estudios arqueológicos realizados hasta ahora en la sierra del departamento de la Libertad, permiten intuir en la existencia de distintas agrupamientos o núcleos poblacionales prehispánicos, formados alrededor de cerros o huacas naturales con filtraciones de agua como es el caso de Yanahuanca y Shulcahuanca en el actual territorio de Quiruvilca, donde destacan las investigaciones efectuadas por Krzanowski (2006), cerro Ichal en San José de Porcón entre Cachicadán, Quiruvilca y Huamachuco, y Huallio entre Cachicadán y Santa Cruz de Chuca, este último rodeado de una densa población establecida en Sagarball, Paibal, Choruro, Charagbal, Las ventanas, Paccha, Tambillo, Caucallate, etc., dedicada al cultivo y agricultura de productos altoandinos (papa, mashua, oca, papa, tarwi, quinua, etc.), crianza y reproducción de camélidos, labores artesanales de orfebrería, textilería, alfarería, etc., compartiendo una unidad geográfica propia de una cultura local, contemporánea con Cajamarca, Huamachuco, Recuay, que recibieron impacto de la cultura Wari, e influencia en el patrón funerario de mausoleos y ventanillas propios del estilo Cajamarca.

La alteración de las distintas estructuras arqueológicas mencionadas en el presente reporte, ocurrieron en la época colonial, tal como indica la versión de los padres agustinos que llegaron al cerro "Guallio" y entraron a un subterráneo en busca de ídolos. De esta manera se puede deducir que los mausoleos y tumbas hechas en piedras labradas, fueron saqueados por extirpadores de idolatrías y buscadores de tesoro, quedando dispersos las tapas de las tumbas y otros elementos estructurales y, las matrices de las tumbas convertidas en pozos de agua que se acumula en época de lluvia. La presencia del conjunto de estructuras, permite sostener en un complejo funerario semejante a una necrópolis, con mausoleos, tumbas, lugares de ofrenda, espacios ceremoniales y estructuras habitacionales que requieren de un mejor y mayor estudio, en beneficio de los pobladores del lugar.

El patrón de asentamiento disperso en la cima de los cerros Huallio, Chiragbal y cerros aledaños, como ocurre en otras partes del área andina, es una respuesta estratégica del antiguo poblador prehispánico, frente a los embates de la naturaleza, fundamenta la razón social de ocupar espacios sin riesgo de huaycos, inundaciones, deslizamiento de terreno y de fácil escurrimiento o drenamiento de agua en tiempo de lluvia.

\section{Agradecimiento y Reconocimiento}

Expreso profundo reconocimiento a Valvina Miñano Reyna, Luzdemio Arteaga Siccha y Antonio Vilchez García, amigos y compañeros de estudio en el cole- 
gio Cesar Vallejo anexo de Cachicadán (hoy Andrés Avelino Cáceres), por motivar la vista orientada a valorar la importancia histórica de los restos arqueológicos que se esconde en las entrañas del cerro Huallio.

\section{Referencias citadas}

Agustinos

1918 Relación de la religión y ritos del Perú, hecho por los primeros religiosos agustinos que allí pasaron para la conversión de los naturales. Informaciones acerca de religión y gobierno de los incas. Colección de libros y documentos referentes a la Historia del Perú, XI: 3-56. Imprenta y librería San Marti y Cia. Lima.

Briceño Rosario, Jesús

2006 Angasmarca y la tradición religiosa Kotosh. Una Arqueología de la mirada. Revista del Museo de Arqueología, Antropología e Historia, 9: 275-296. Universidad Nacional de Trujillo.

Castro de Trelles, Lucila

1992 Relación de la religión y ritos del Perú hecho por los padres agustinos. Edición, estudio preliminar y notas. L.C. de Trelles/editora. Pontificia Universidad Católica del Perú.

Cieza de León, Pedro

1996 La crónica del Perú. Fondo Editorial Pontificia Universidad católica del Perú-Academia Nacional de História.

Cossio, Aurelio

1964 Geología de los cuadrángulos de Santiago de Chuco y Santa Rosa. Boletín $\mathrm{N}^{\circ} 8$ (hojas 17-g y 18 - g). Dirección de Minería, Ministerio de Fomento y O.P, Republica del Perú.

Horkheimer, Hans

1944 Vistas arqueológicas del noroeste del Perú: 37-40. Librería e imprenta Moreno, Trujillo-Perú

Krzanowski, Andrzej

2006 Sitios arqueológicos en la región de Alto Chicama. Poska Akademia Umiejetnosci:

Paz Sondan, Mateo

1862 Geografía del Perú. R.R. Golder Asociates

Pérez Calderón, Ismael

2012 Patrimonio Cultural de la Nación: Monumentos arqueológicos de Santiago de Chuco. Consejo Nacional de Ciencia y Tecnología, Lima.

1994 Monumentos arqueológicos de Santiago de Chuco, la Libertad. Boletín de Lima, 91-96: 225-274, Editorial los Pinos, Lima.

1986 Catastro arqueológico en Santiago de Chuco: Tesis para optar el título de Licenciado en Arqueología. Universidad Nacional de Trujillo. 
1986a Cerro Huayllio adoratorio prehispánico en Santiago de Chuco. Santiago de Chuco y su feria. Revista Anual de Cultura, 1. Ciudad Vallejo. Trujillo-Perú.

Ponce de León, Isabel; Ismael Pérez Calderón y Walter Flores Sánchez 1980 Prospección arqueológica en cerro Saloganda, Santiago de Chuco. Informe del curso de práctica pre profesionales. Facultad de Ciencias Sociales, Universidad nacional de San Cristóbal de Huamanga.

Stiglish, Germán

1922 Diccionario Geográfico del Perú. Imprenta Torres Aguirre Lima.

Ravines, Rogger

1984 Cajamarca Prehispánica, inventario de monumentos arqueológicos. INC-CORDE Cajamarca. 1ra edición.

2010 Pinturas rupestres de Cungayo, Quiruvilca, La Libertad, 2003. Boletín de Lima, 162: 49. Editorial Los Pinos. Lima

2017 Las canteras de Tres cruces, Quiruvilca. Boletín de Lima, 188: 61-156. Editorial Los Pinos. Lima

Raymondi, Antonio

1965 El Perú. Editores Técnicos Asociados SA. Lima.

Reichlen, Henry y Paule Reichlen

1949. Recherches archaeologiques dance les andes de Cajamarca. Journal de la Societe des Americanistes, XXXVIII:137-174. Paris.

Tello, Julio C.

2004 Arqueología de Cajamarca: Expedición al Marañón-1937. Obras completas Volumen I, Clásicos Sanmarquinos. COFIDE, Grupo Santander Perú, Centro Cultural UNMSM, Museo de Arqueología y Antropología UNMSM y Fondo Editorial de la UNMSM. Lima.

Topic, Jhon R; Theresa Lange Topic y Alfredo Melly Cava.

2002 Catequil the Archeology Etnohistory and Etnography of the Major Provincial Huaca. Andean Archeology I: 303-336. Isbell and Silverman/editores. Kluwer Academic/Plenum Piblishers. New York Boston, Dardrecht, London, Moscow.

Velásquez Inca, Fidel

2009 Monografía: La Tierra de Cachicadán, distrito Termo medicinal. Industria Gráfica S.A.C, Trujillo-Perú.

Villanueva Basilio, Antonio

2005 Cachicadán: Geohistoria y sus riquezas. Grupo Editor Amauta, Trujillo-Perú.

Zaki, Andrzej

1983 "Cultura Pelón, una desconocida cultura en la Sierra Norte. Boletín de Lima, 29: 13-19. Editorial Los Pinos. Lima. 